\title{
Investigation on Surface Tilting in the Failure Process of Shallow Landslides
}

\author{
Shifan Qiao ${ }^{1}$, Chaobo Feng ${ }^{1}$, Pengkun Yu ${ }^{1}$, Junkun Tan ${ }^{1}$, Taro Uchimura ${ }^{2}$, Lin Wang ${ }^{3}$, \\ Junfeng Tang ${ }^{2}$, Quan Shen ${ }^{4}$ and Jiren Xie ${ }^{1, *}$ \\ 1 Department of Civil Engineering, Central South University, Changsha 410075, China; \\ qiaosf@csu.edu.cn (S.Q.); fengchaobo@csu.edu.cn (C.F.); frankyupk@csu.edu.cn (P.Y.); \\ 184801006@csu.edu.cn (J.T.) \\ 2 Department of Civil and Environmental Engineering, Saitama University, 255 Shimo-Okubo, Sakura-ku, \\ Saitama 338-8570, Japan; uchimura@civil.t.u-tokyo.ac.jp (T.U.); tang.j.360@ms.saitama-u.ac.jp (J.T.) \\ 3 Chuo Kaihatsu Corporation, Nishiwaseda1-13-5, Shinjuku, Tokyo 169-8612, Japan; wang@ckcnet.co.jp \\ 4 Department of Civil Engineering, Hunan University of Technology, Zhuzhou 412000, China; \\ shenquan123456@csu.edu.cn \\ * Correspondence: jirenxie198911@csu.edu.cn
}

Received: 14 February 2020; Accepted: 1 May 2020; Published: 6 May 2020

check for updates

\begin{abstract}
In recent decades, early warning systems to predict the occurrence of landslides using tilt sensors have been developed and employed in slope monitoring due to their low cost and simple installation. Although many studies have been carried out to validate the efficiency of these early warning systems, few studies have been carried out to investigate the tilting direction of tilt sensors at the slope surface, which have revealed controversial results in field monitoring. In this paper, the tilting direction and the pre-failure tilting behavior of slopes were studied by performing a series of model tests as well as two field tests. These tests were conducted under various testing conditions. Tilt sensors with different rod lengths were employed to investigate the mechanism of surface tilting. The test results show that the surface tilting measured by the tilt sensors with no rods and those with short rods located above the slip surface are consistent, while the tilting monitored by the tilt sensors with long rods implies an opposite rotational direction. These results are important references to understand the controversial surface tilting behavior in in situ landslide monitoring cases and imply the correlation between the depth of the slip surface of the slope and the surface tilting in in situ landslide monitoring cases, which can be used as the standard for tilt sensor installation in field monitoring.
\end{abstract}

Keywords: tilting sensor; slope failure; tilt direction; landslides; early warning systems

\section{Introduction}

Landslides frequently occur around the world every year and pose a large threat to people's lives and property. Typical methods for landslide prevention, such as retaining walls and ground anchors, have been employed to reduce the damage caused by landslides. However, these typical methods are costly and not suitable for a large number of slopes with potential risks of failure.

On the other hand, some early warning systems have been proposed based on the correlation between the rainfall intensity and risk of landslides [1-4]. These early warning systems work well in evaluating the likelihood of potential landslides in a region, but they are not effective in predicting a specific landslide within a region. Rainfall can change the soil moisture content, which can then affect the soil strength and trigger a landslide. Other early warning systems were also developed using the soil moisture index [4]. However, the relationship between the soil moisture content and stability of slopes is abstruse. 
When a soil slope is deformed, energy is released in the form of elastic waves owing to the movement or fracturing of soil particles. Hence, some researchers focus on the application of acoustic emission (AE) technology in the monitoring of landslides to capture elastic waves [5-11]. However, the effectiveness of such systems to predict landslides is still under investigation. The installation of these systems is also complicated as a borehole and an active waveguide are needed.

Ground-based interferometric synthetic aperture radar (GB-InSAR) is a new tool that has been used to monitor landslide motion and can reduce losses caused by landslides by providing early warnings [12-14]. However, the cost of this type of monitoring system is also expensive for wide usage.

Typical monitoring systems of landslides monitor the displacement of soil from slopes [12,15-21] by utilizing conventional geotechnical monitoring methods, such as wire extensometers, borehole tilt meters or inclinometers. Some prediction methods for these types of early warning systems have also been proposed [22-27]. However, the inconvenience of installation and maintenance of these monitoring systems $[28,29]$ limits their wide-scale application.

Reducing costs and price is still a primary concern in the application of early warning systems. The prices of some measuring equipment, such as extensometers, borehole tilt meters or devices to build acoustic emission monitoring systems, are still too high, which makes the price of the entire monitoring system unacceptable for wide-scale applications. Cable connections for such types of systems are also inconvenient for installation and difficult to maintain, which may also increase the cost.

In recent years, with the development of microelectronic techniques, early warning systems utilizing MEMS (microelectromechanical systems) technology have been proposed to monitor and estimate the risk of slope failure [28-43]. Compared to conventional instruments used to monitor landslides, MEMS sensors, such as accelerometer sensors [30-32] and tilt sensors [33-39], are small, inexpensive and sophisticated, which also greatly reduces the cost of building early warning systems. The low-power radio communication and modular design make the installation and maintenance of the whole system more convenient than cable-connected devices, and the data transmission is more efficient. De Dios et al. [33] and Marciano Jr [34] proposed a landslide monitoring system composed of a "sensor column" buried vertically underground in a borehole. The sensor column consists of pipe segments, each containing triaxial accelerometers for measuring tilt and capacitive sensors for water content measurements. Measurements of the internal deformation taken in each segment are accessed via a controller area network (CAN) communications protocol. However, the tilt meter in the borehole is not convenient to install owing to the requirement of a borehole.

Different systems based on monitoring the tilting behavior of the soil surface with inexpensive and sophisticated sensors have been proposed [28-30]. The tilt sensors in the monitoring systems proposed by Dikshit et al. [36] are buried under the soil surface. The tilt sensors in the monitoring systems for shallow landslides proposed by the authors [37-39] are attached to a rod insert into the unstable soil layer on the slope surface at a depth of approximately $1 \mathrm{~m}$ or more. Accordingly, the tilting behavior reveals the movement of the rod with the landslide mass, and the installation is much simpler than that of a tilt meter. A series of model tests and field tests were conducted. The results show a correlation between the abnormal behaviors in the tilting history on the slope surface and the slope failure [39-43]. However, some tilt sensors located above the slip surface of the landslides with rotational components tilted backward when the slope was sliding, while the tilt sensor together with a rod reaching the slip surface of slopes tilted forward during the failure process [42]. This phenomenon may be mainly affected by the length of the rod. If the rod is long enough to insert into the stable layer, the upper part of the rod will rotate with the landslide mass, which leads the tilt sensor to tilt forward. If the rod is short, the tilt sensor will rotate with the landslide mass. Although this behavior has been detected, there are few studies exploring this problem.

In this paper, to investigate the tilting behavior of tilt sensors with different rod lengths as landslides develop, a series of model tests were conducted, and different experimental parameters were considered. In addition, two field tests were also carried out, in which slope failure was triggered by artificial rainfall. In all of these tests, the tilting behaviors of the slopes along the slope direction 
were monitored by tilt sensors connected to a data logger for continuous data recording. The frequency for data sampling in the model tests and the field tests was $1 / 60 \mathrm{~Hz}$.

\section{Proposed Equipment for Slope Monitoring}

The early warning system proposed by the authors consists of a group of sensor units and a gateway unit for a slope region, as shown in Figure 1. The sensor units are installed at shallow depths on the slope, and these units are designed to be wireless. The sensor units periodically measure the condition of the slope at 10 min intervals. The collected data are transferred from the tilt sensors to the gateway unit by radio communication, and then are sent to a data server on the internet through a cellular network. Then, the data can be browsed on the website and will also be processed on the server. If an abnormal behavior in the slope is detected, a warning will be issued.

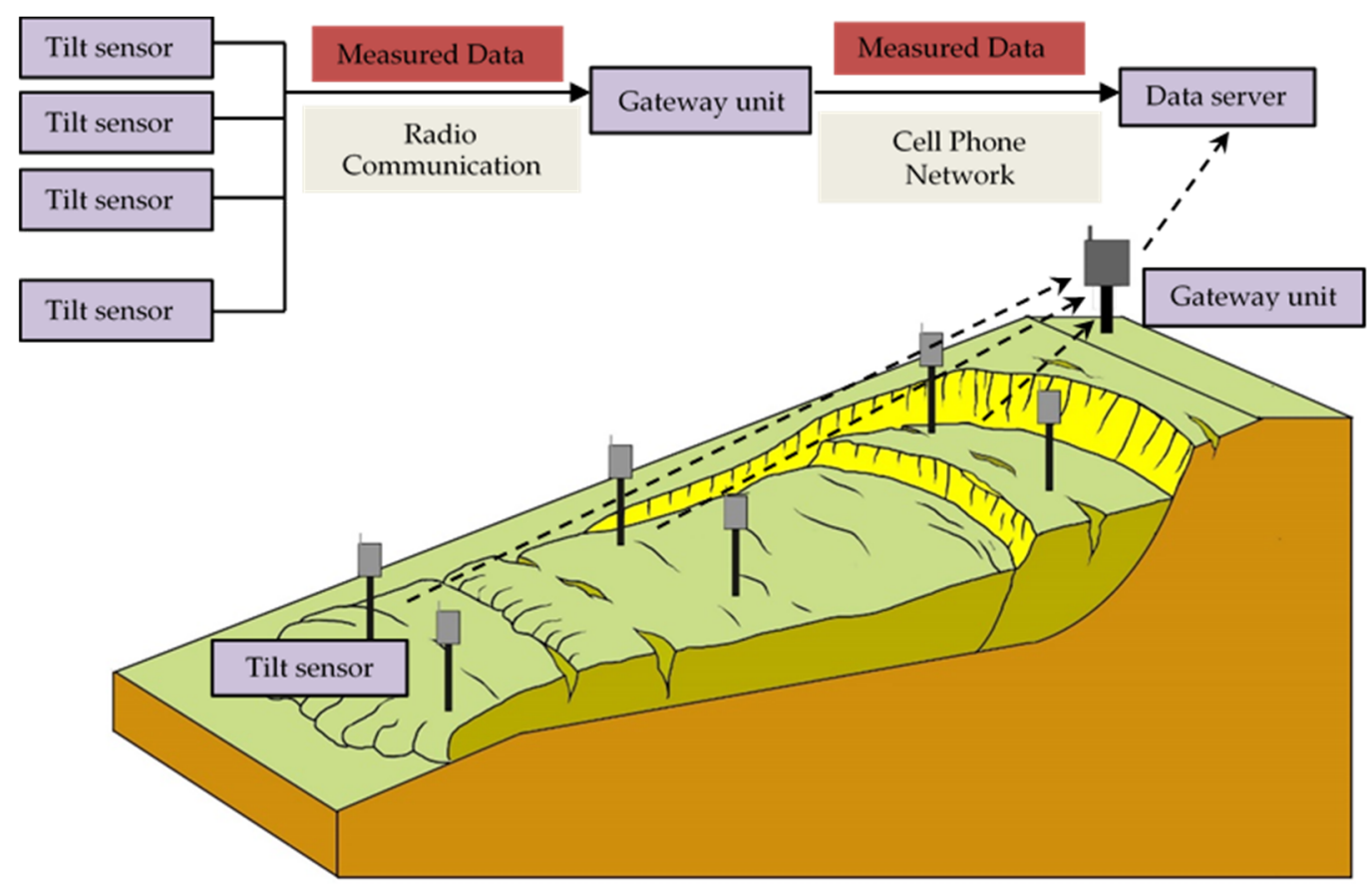

Figure 1. Outline of the wireless monitoring and early warning system for slope failures.

As shown in Figure 2, the surface tilt sensor developed by the authors is equipped with a MEMS tilt sensor (nominal resolution $=0.0025^{\circ}=0.04 \mathrm{~mm} / \mathrm{m}$ ). An additional temperature sensor is also used for temperature compensation in the tile sensor. Each sensor unit is powered by $4 \mathrm{AA}$ alkaline batteries and functions well in the field for a duration of more than one year. By connecting an optional solar battery, which costs approximately 5 USD, the sensor unit can work semi-indefinitely. The tilt sensor is attached to a rod vertically installed in the slope surface. 


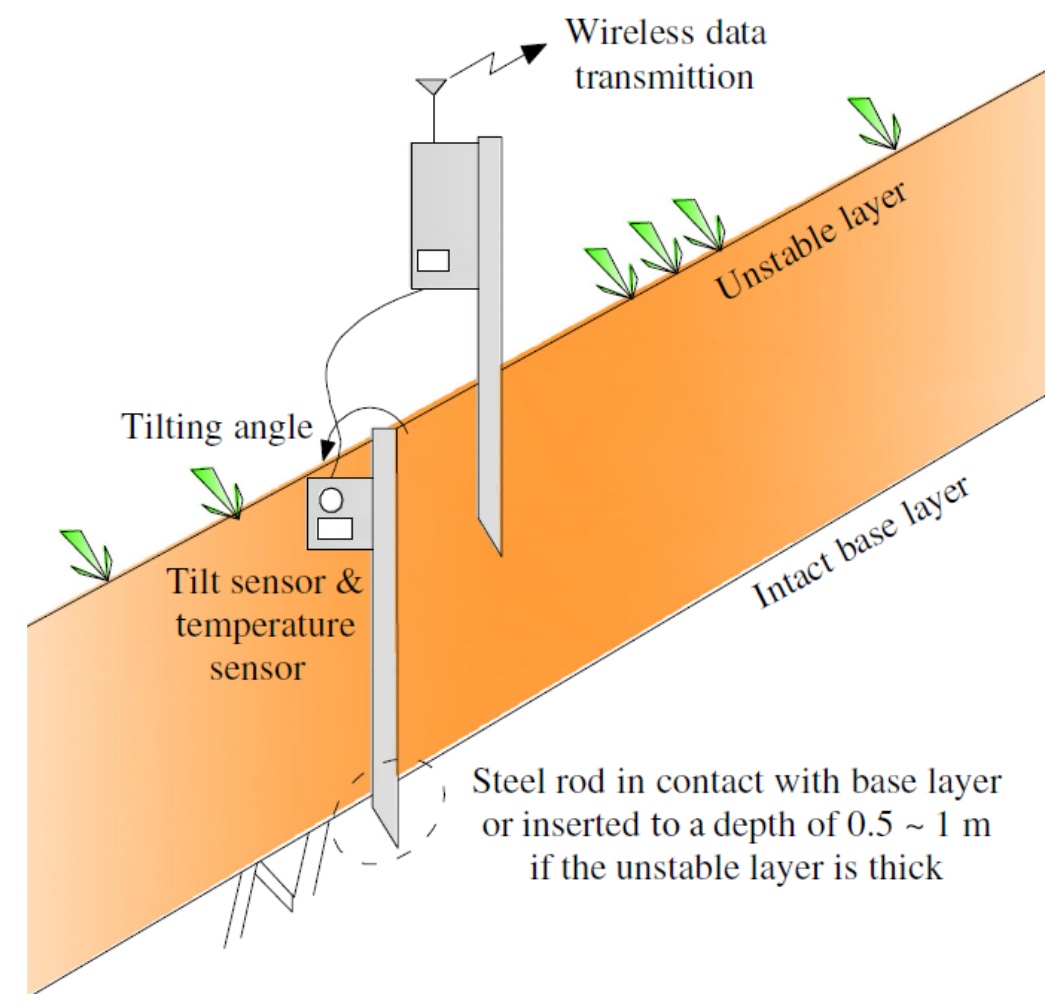

Figure 2. Early warning system using slope tilting.

\section{Methodology}

To investigate the tilting behavior of tilt sensors under the conditions of different experimental parameters, the current investigations involved ten small-scale model tests using tilt sensors without rods, five small-scale tests model using tilt sensors with short rods, two small-scale model tests using tilt sensors with long rods and two field tests.

\subsection{Laboratory Model Tests}

The slope model in these tests was built in a rectangular box, measuring $1165 \mathrm{~mm}$ (length) $\times$ $450 \mathrm{~mm}$ (width) $\times 380 \mathrm{~mm}$ (height).The soil was divided into two parts: the base layer and the surface layer. The slope construction procedure are presented in Figure 3. First, to make the base layer, the sand used in the model tests was compacted to a certain density by tamping. Then, the base layer was carved into a predesigned shape. The predefined shape was curvilinear and consisted of a semicircle parts or two circular parts with specified radii. After this step, the surface layer was built using the same sand used to build the base layer with the specified density. A polyethylene sheet was placed between the base layer and surface layer and acted as the predefined slip surface of the slope models before the surface layer was built, as polyethylene can reduce friction and restrict water flow. After building the slope model, tilt sensors were installed in the designated position, which are illustrated in Figures 4-6. In addition, an extra tilt sensor was fixed on the wooden box to measure the tilting angle of the box. In addition, in contrast to other model tests, a planar slip surface was built to investigate the tilting behaviors in translational landslides in test 10. Considering that the complex curve of landslides can be decomposed into different arcs with different radii for simplification, the slip surfaces in the model tests are assumed to be semicircular or are assumed to have two quadrants with different radii. 


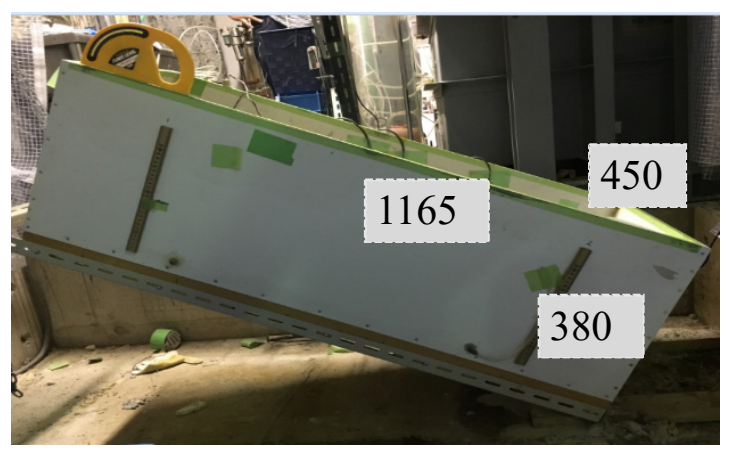

(a)

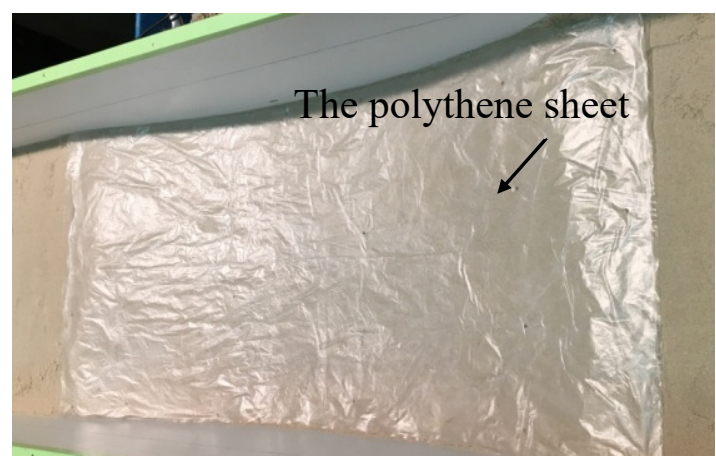

(c)

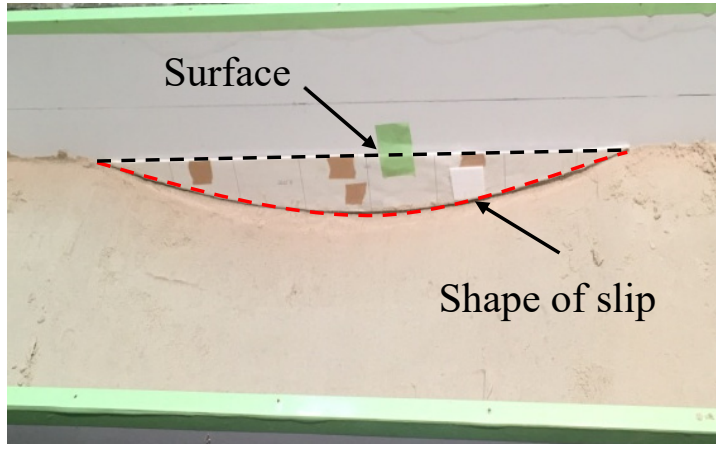

(b)

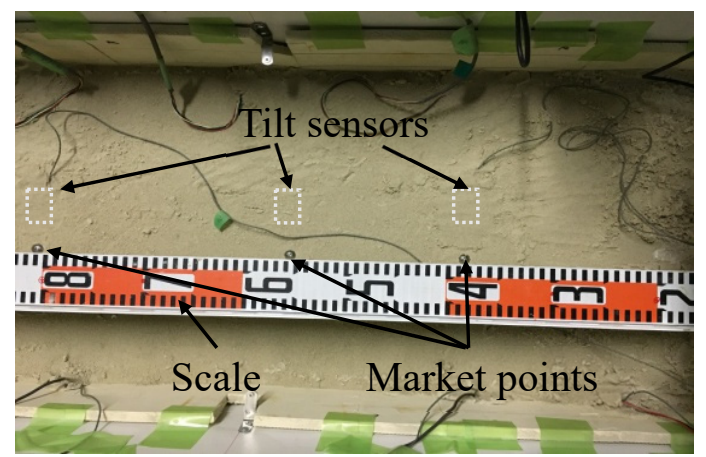

(d)

Figure 3. Images of the laboratory test steps. (a) The dimensions of the container; (b) the creation of the slip surface; (c) the polyethylene sheet; and (d) the built surface layer and the installed instruments.

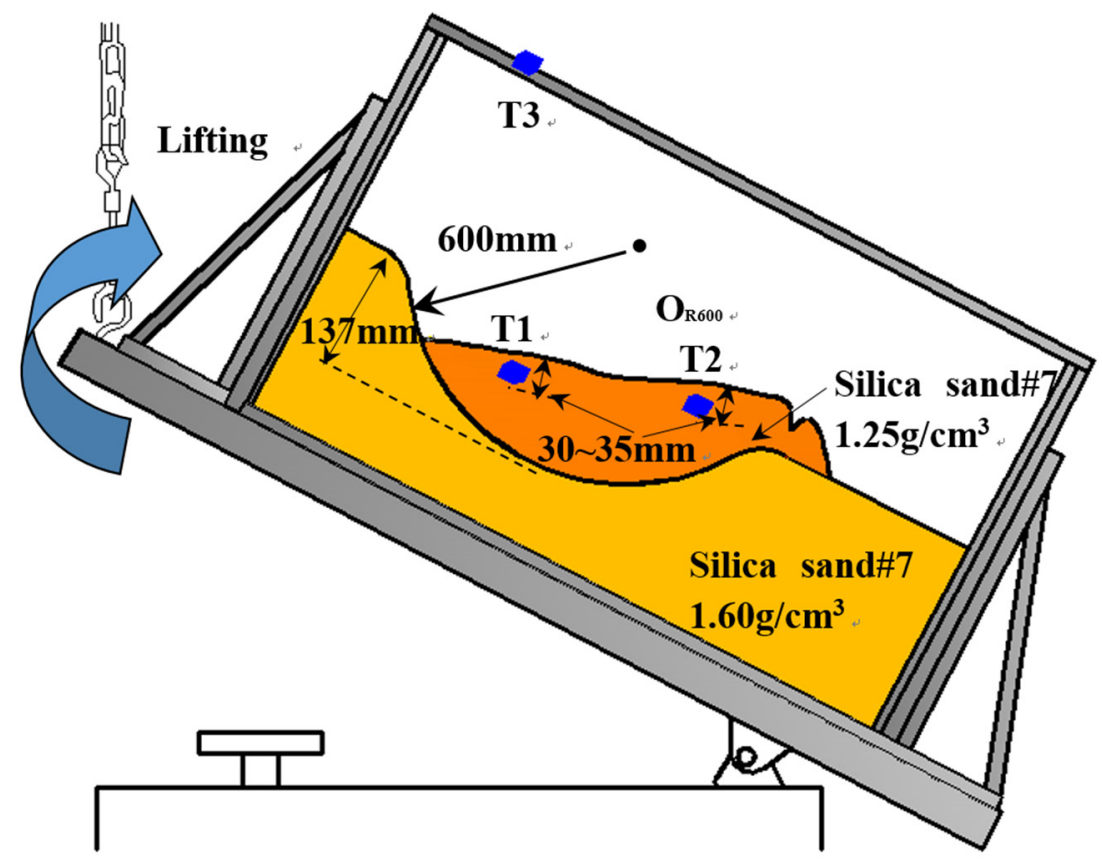

(a)

Figure 4. Cont. 


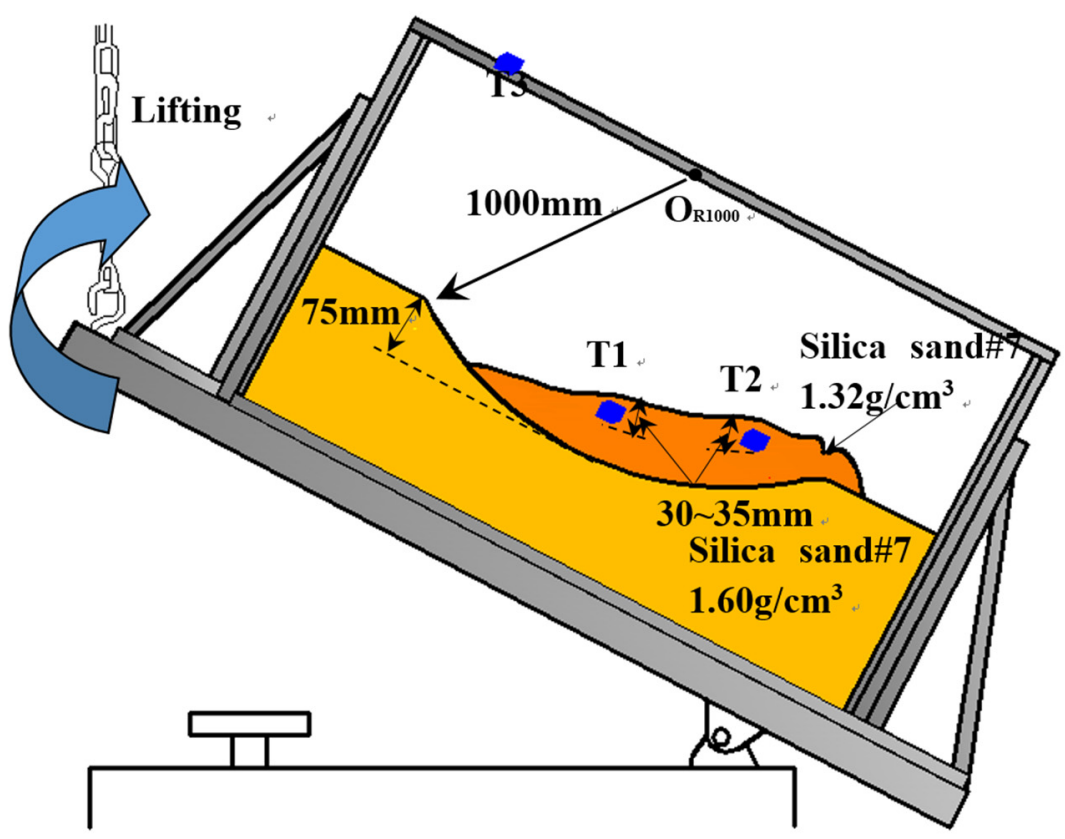

(b)

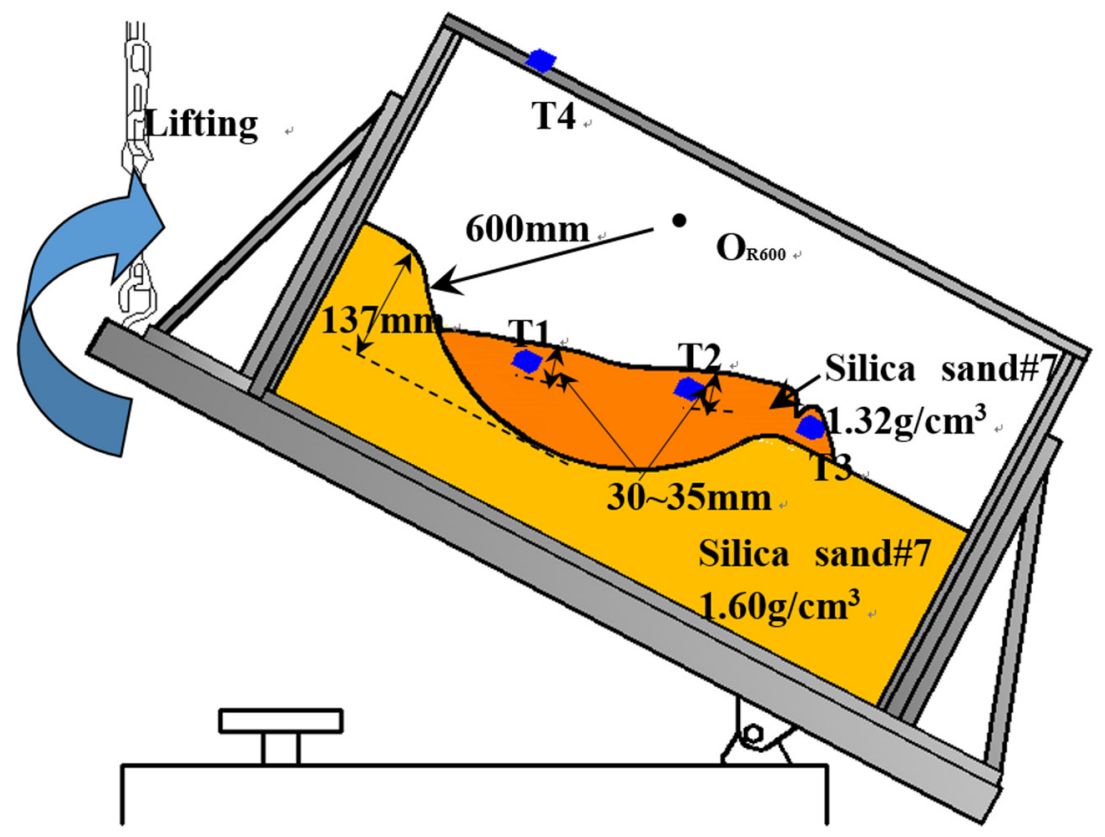

(c)

Figure 4. Cont. 


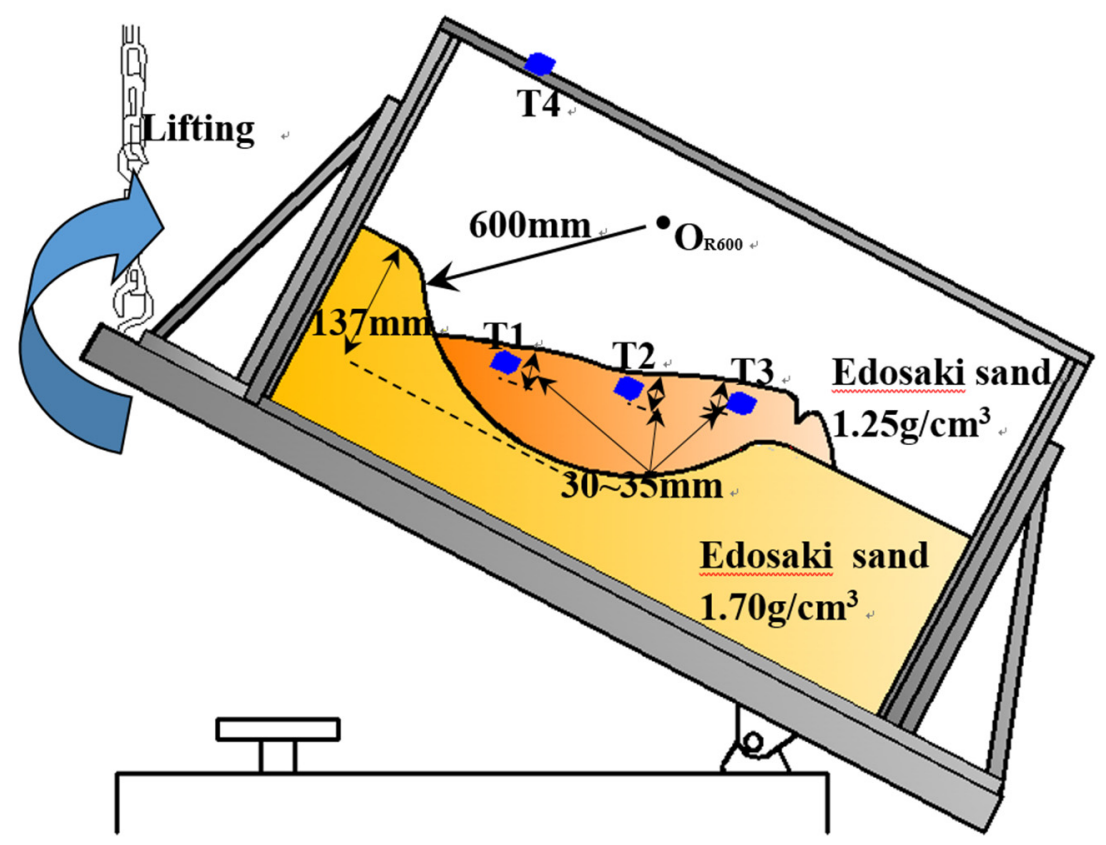

(d)

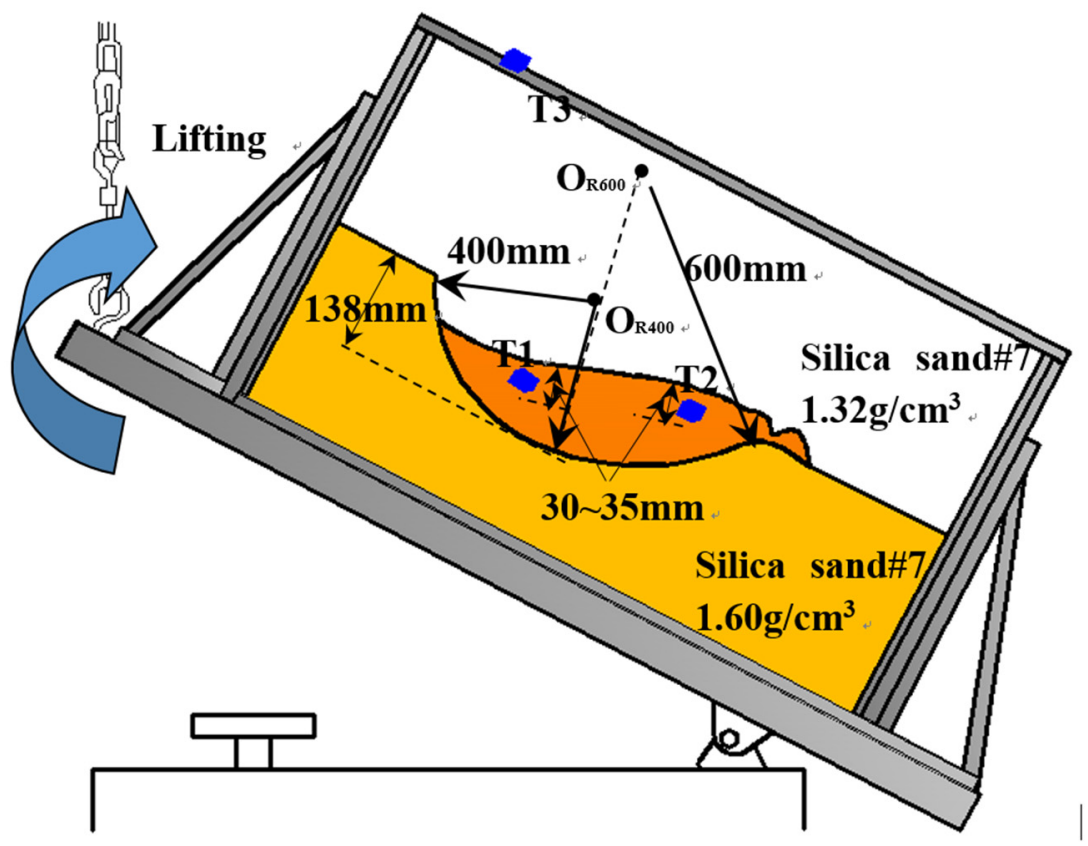

(e)

Figure 4. Cont. 


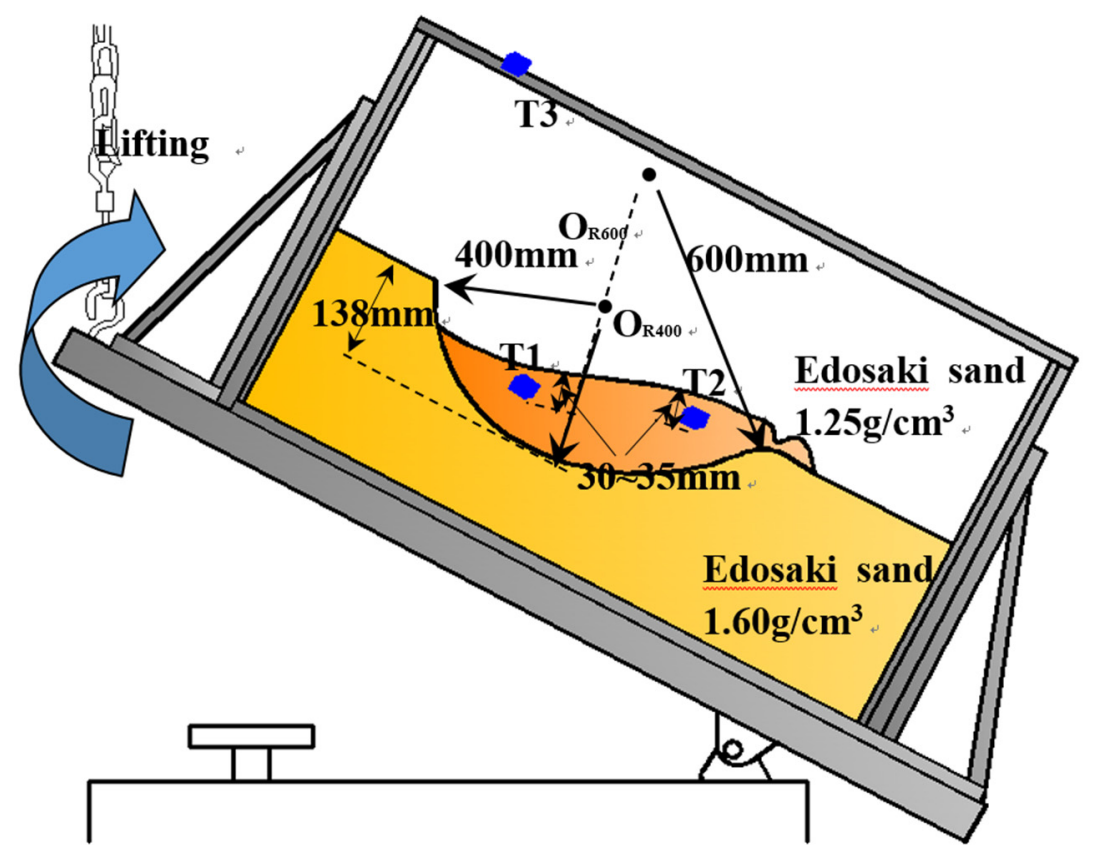

(f)

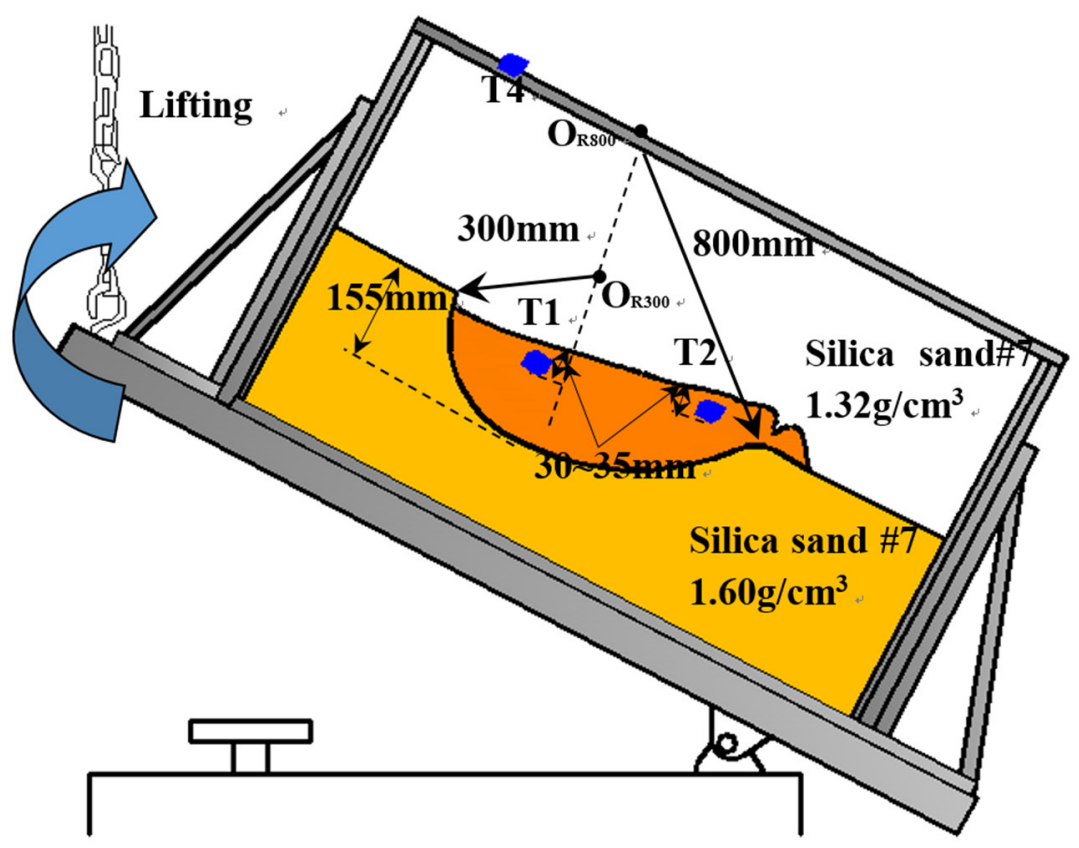

(g)

Figure 4. Cont. 


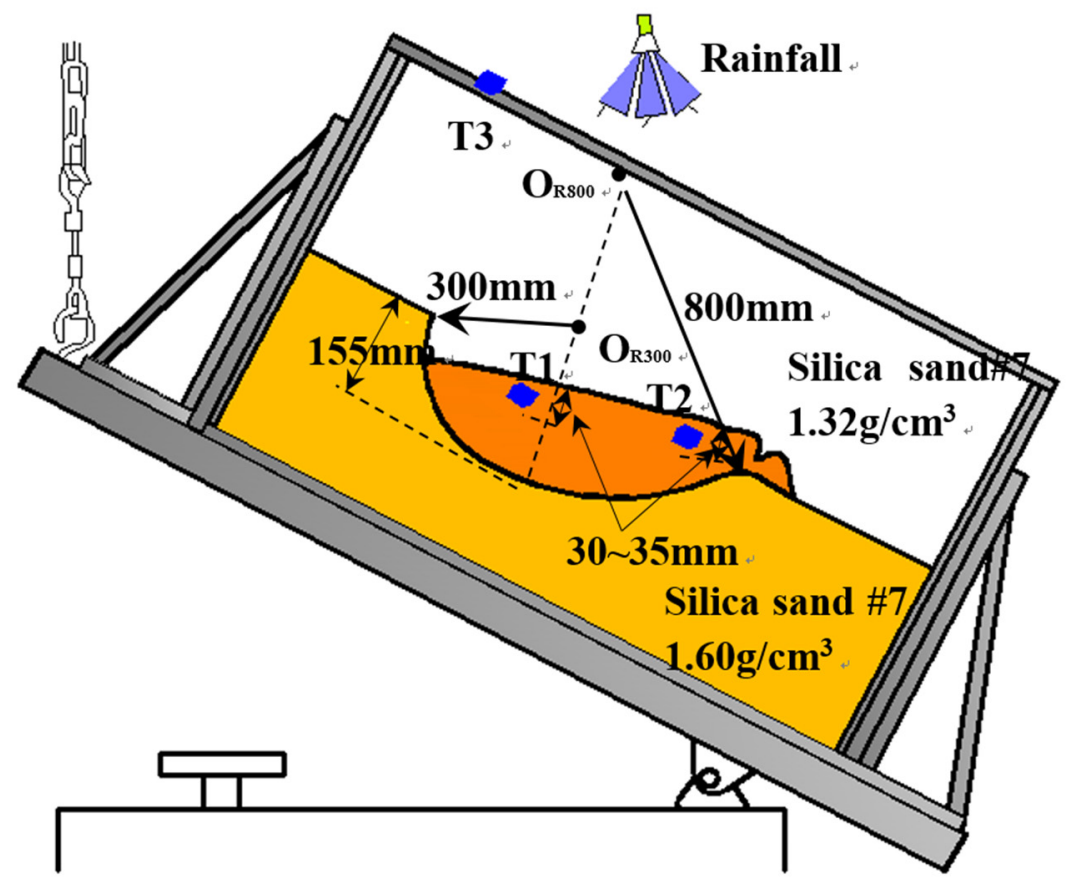

(h)

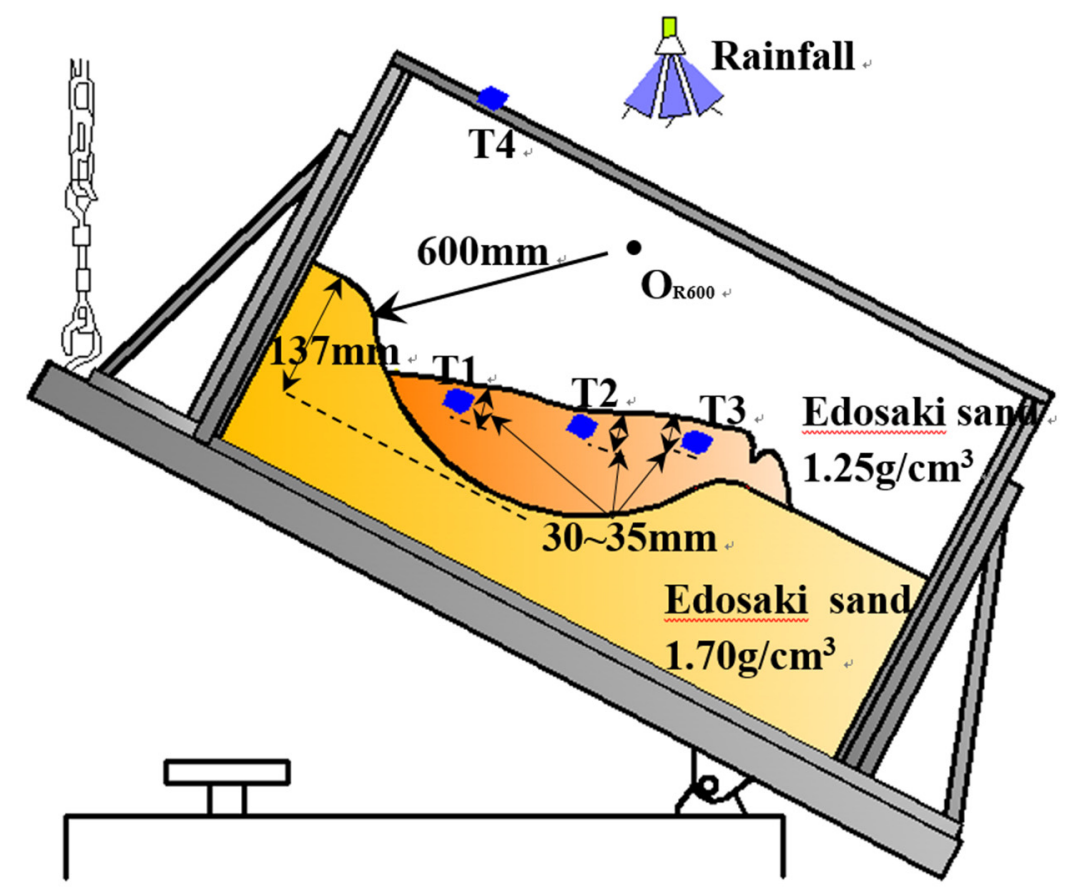

(i)

Figure 4. Cont. 


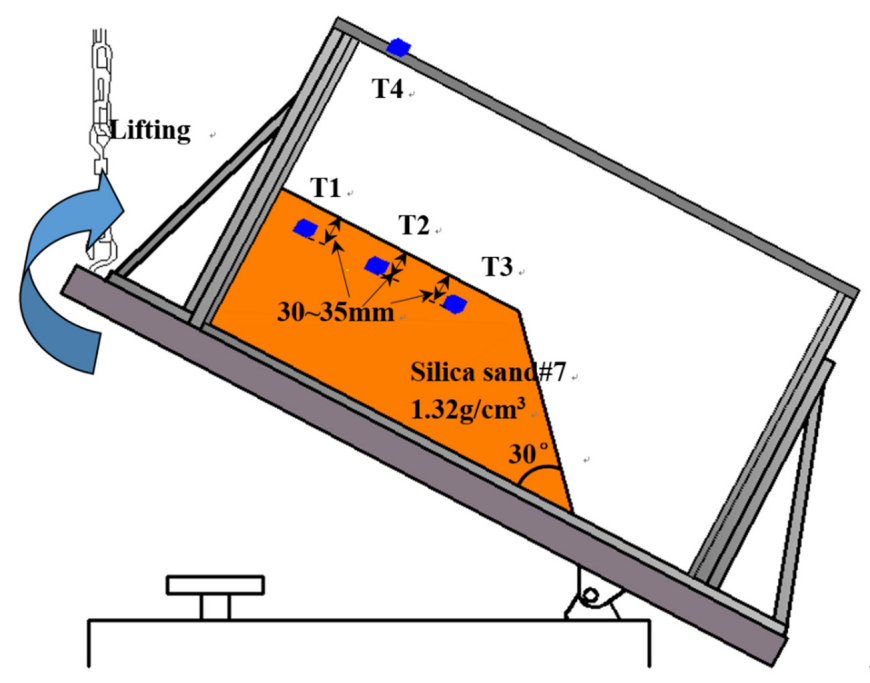

(j)

Figure 4. The cross sections of the slope models and the setups of the apparatuses in Test 1 to Test 10 as shown from (a) to $(\mathbf{j})$.

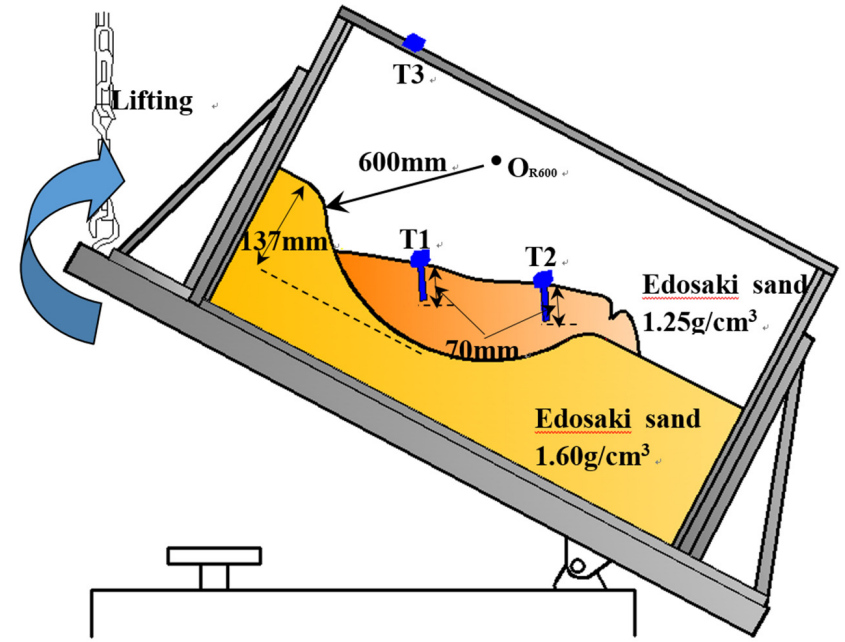

(a)

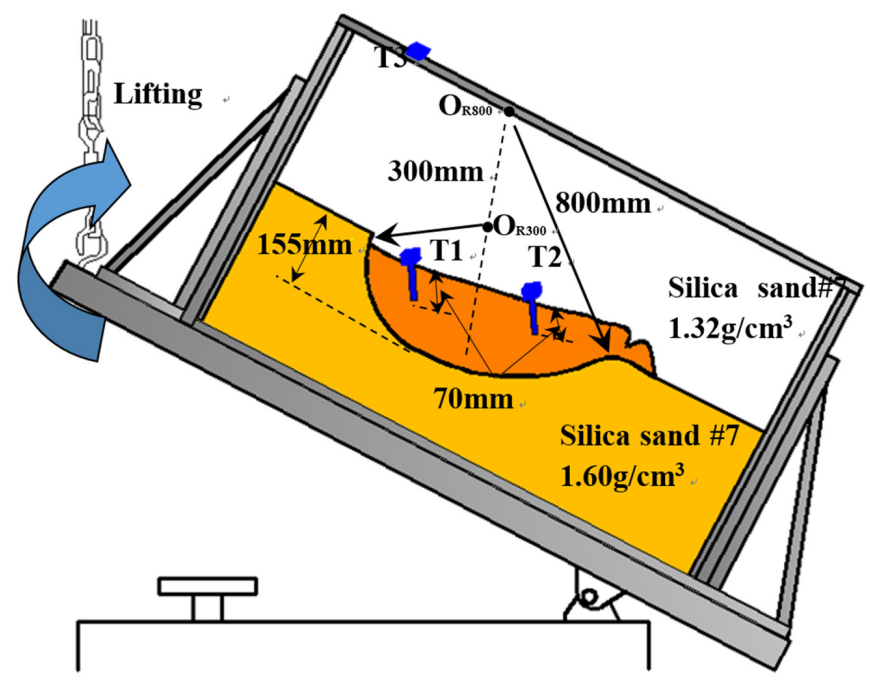

(b)

Figure 5. Cont. 


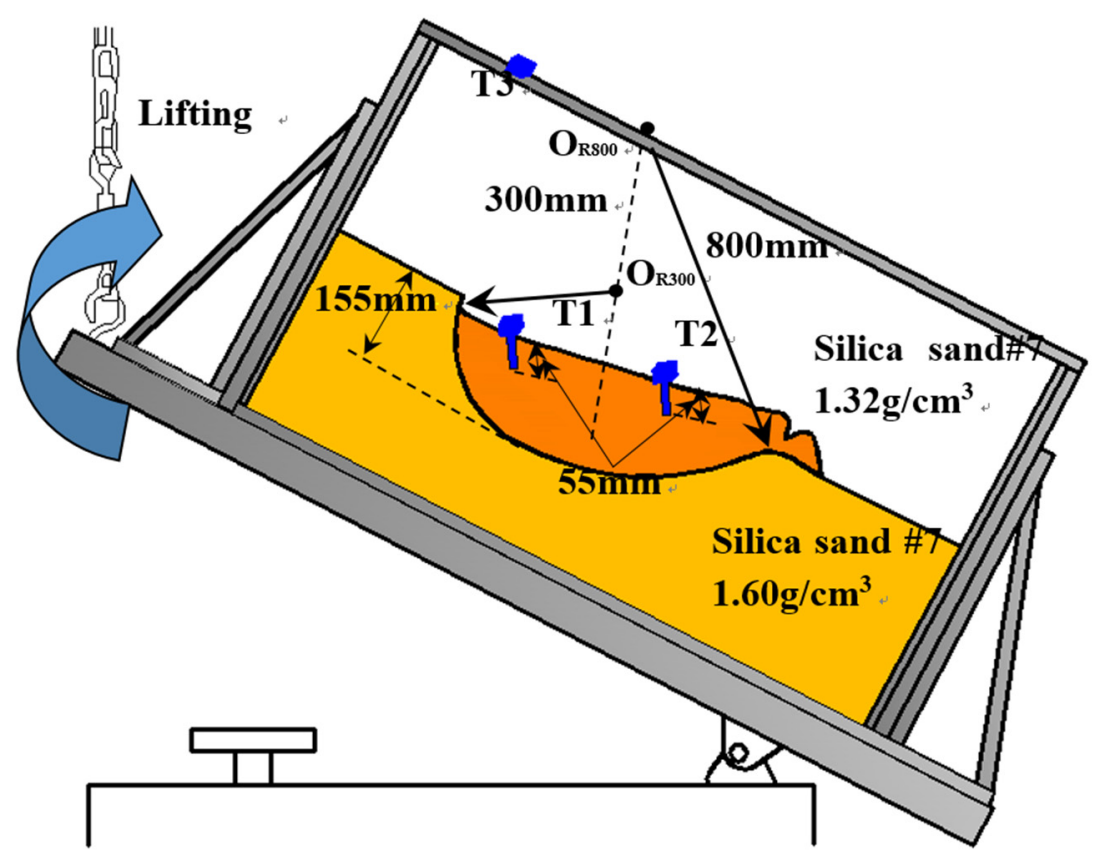

(c)

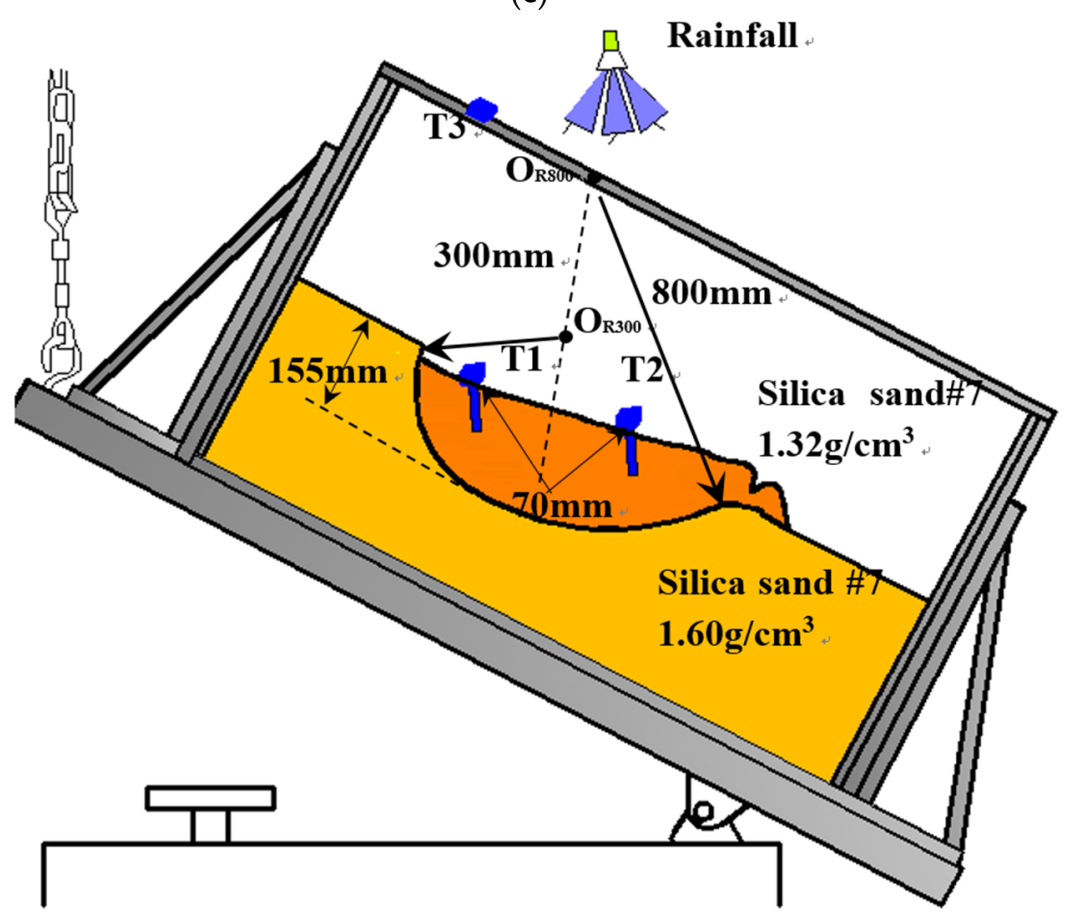

(d)

Figure 5. Cont. 


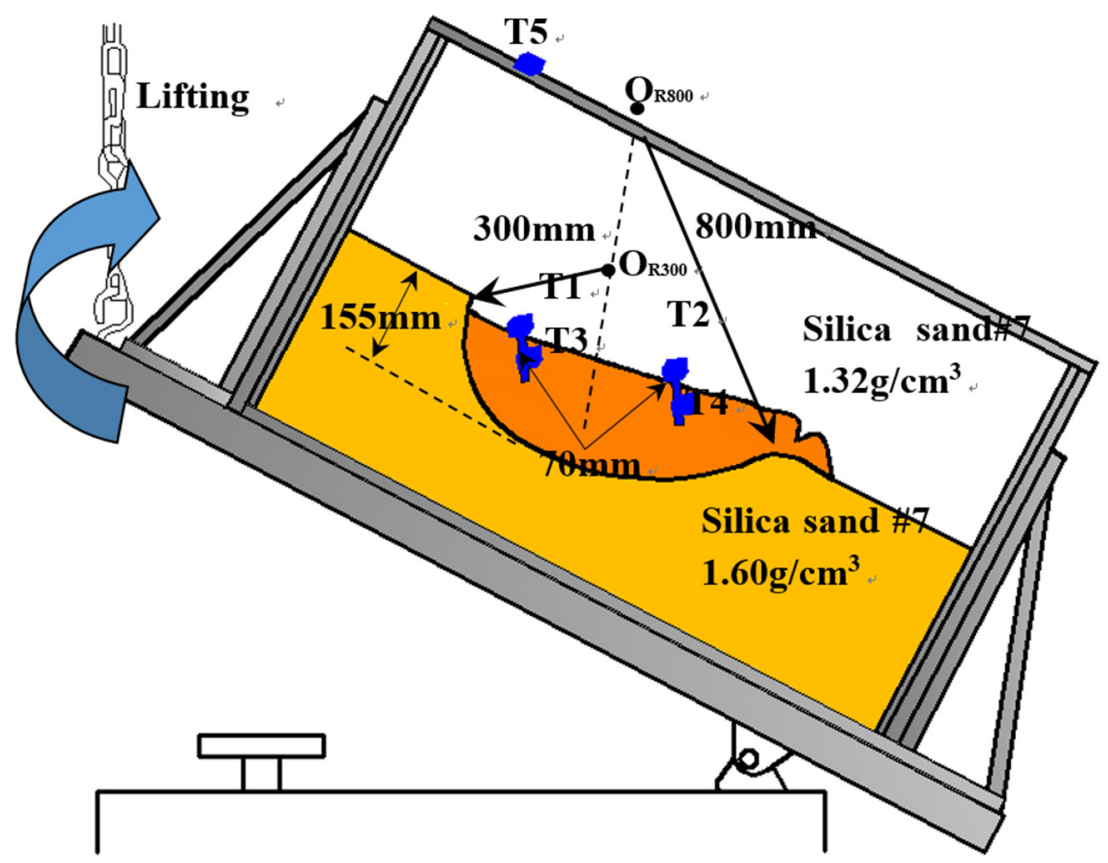

(e)

Figure 5. The cross sections of the slope models and the setups of the apparatuses in Test 11 to Test 15 as shown from (a) to (e).

Two landslide-triggering factors were considered in the model tests: artificial rainfall and inclining the slope by lifting one end of the wooden container step-by-step. At the same time, an external tilt sensor was attached to the container to measure the tilting angle of the box to calibrate the tilt angle of the sensor when the wooden container was inclined and to record the initial angle of the container when using the artificial rainfall method to trigger a landslide. As the trigger factor is active, the tilting behaviors were obtained by recording the data transferred from the tilt sensors.

All of the details of the model test mentioned above are shown in Figure 3, and the type of sands and their relative densities, the radii of the predefined slip surfaces and the landslide-triggering factors designed for each model test are introduced in detail in Tables 1-3.

Table 1. Small-scaled tests using tilt sensors without rods.

\begin{tabular}{|c|c|c|c|c|c|c|}
\hline Test No. & Material & $\begin{array}{l}\text { Radius of the Slip } \\
\text { Surface R or R1 + } \\
\text { R2 (mm) }\end{array}$ & $\begin{array}{l}\text { Triggering } \\
\text { Factor }\end{array}$ & $\begin{array}{c}\text { Base Layer } \\
\text { Density } \\
\left(\mathrm{g} / \mathrm{cm}^{3}\right)\end{array}$ & $\begin{array}{c}\text { Surface Layer } \\
\text { Density }\left(\mathrm{g} / \mathrm{cm}^{3}\right)\end{array}$ & Depth (mm) \\
\hline 1 & Silica sand \#7 & R: 600 & Lifting & 1.60 & 1.25 & 137 \\
\hline 2 & Silica sand \#7 & R: 1000 & Lifting & 1.60 & 1.32 & 75 \\
\hline 3 & Silica sand \#7 & R: 600 & Lifting & 1.60 & 1.32 & 137 \\
\hline 4 & Edosaki sand & R: 600 & Lifting & 1.70 & 1.25 & 137 \\
\hline 5 & Silica sand \#7 & $\mathrm{R} 1+\mathrm{R} 2: 600+400$ & Lifting & 1.60 & 1.32 & 138 \\
\hline 6 & Edosaki sand & $\mathrm{R} 1+\mathrm{R} 2: 600+400$ & Lifting & 1.60 & 1.25 & 138 \\
\hline 7 & Silica sand \#7 & $\mathrm{R} 1+\mathrm{R} 2: 300+800$ & Lifting & 1.60 & 1.32 & 155 \\
\hline 8 & Silica sand \#7 & $\mathrm{R} 1+\mathrm{R} 2: 300+800$ & Rainfall & 1.60 & 1.32 & 155 \\
\hline 9 & Edosaki sand & R: 600 & Rainfall & 1.70 & 1.25 & 137 \\
\hline 10 & Silica sand \#7 & Infinite (planar) & Lifting & / & 1.32 & / \\
\hline
\end{tabular}




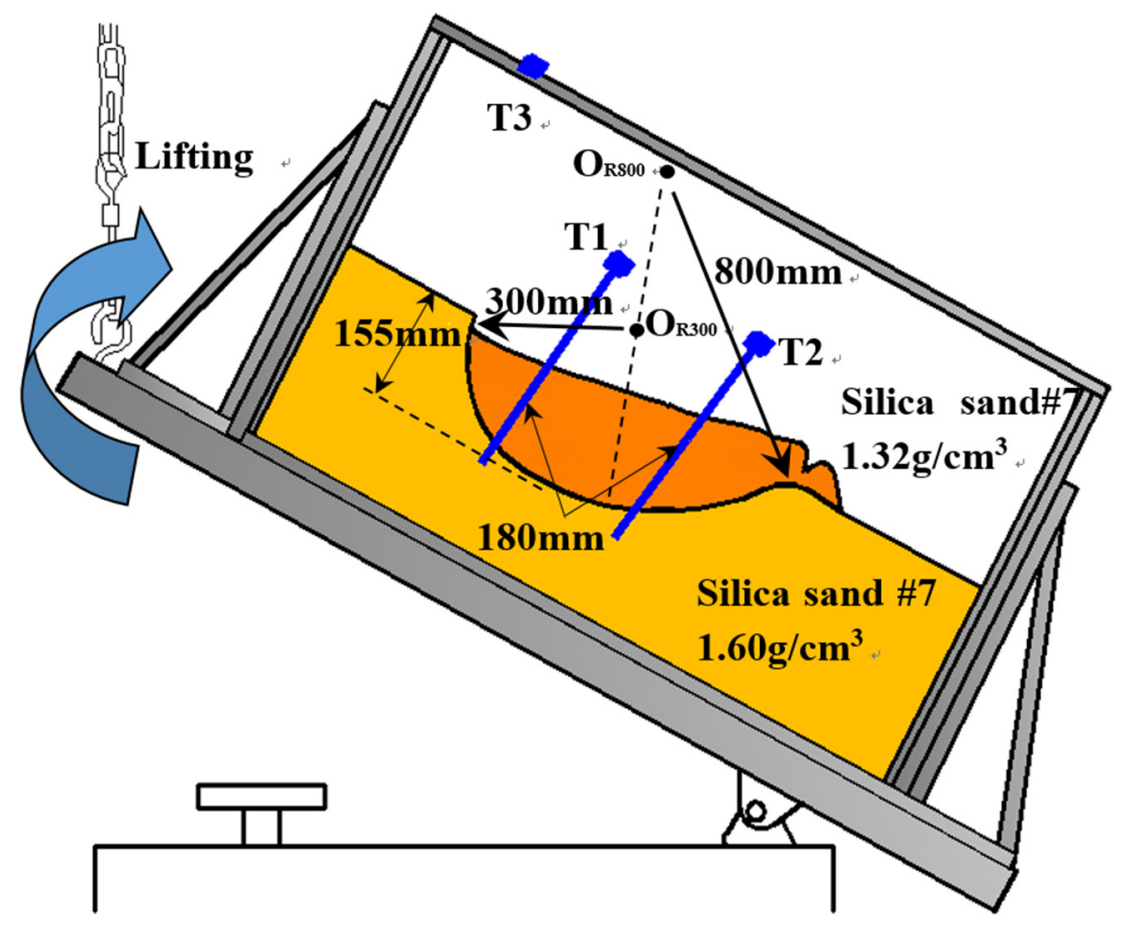

(a)

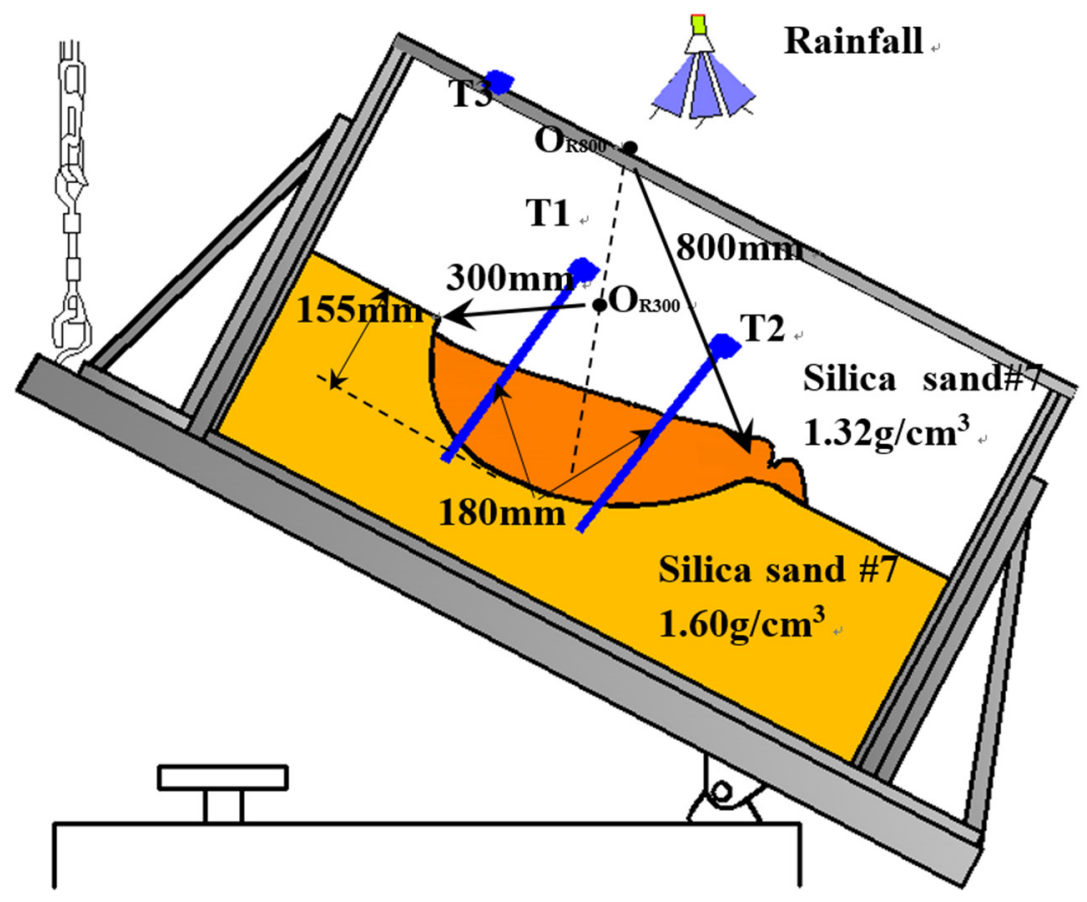

(b)

Figure 6. Illustration of using tilt sensors with long rods reaching the slip surface in (a) Test 16 and (b) Test 17. 
Table 2. Small-scaled tests using tilt sensors with short rods

\begin{tabular}{|c|c|c|c|c|c|c|c|}
\hline Test No. & Material & $\begin{array}{l}\text { Radius of the } \\
\text { Slip Surface } \\
\text { (mm) }\end{array}$ & $\begin{array}{l}\text { Triggering } \\
\text { Factor }\end{array}$ & $\begin{array}{c}\text { Base Layer } \\
\text { Density }\left(\mathrm{g} / \mathrm{cm}^{3}\right)\end{array}$ & $\begin{array}{l}\text { Surface Layer } \\
\text { Density }\left(\mathrm{g} / \mathrm{cm}^{3}\right)\end{array}$ & $\begin{array}{l}\text { Depth } \\
(\mathrm{mm})\end{array}$ & $\begin{array}{l}\text { Rod Length } \\
\text { (mm) }\end{array}$ \\
\hline 11 & Edosaki sand & R: 600 & Lifting & 1.60 & 1.25 & 137 & 70 \\
\hline 12 & Silica sand \#7 & $\begin{array}{c}\mathrm{R} 1+\mathrm{R} 2: 300+ \\
800\end{array}$ & Lifting & 1.60 & 1.32 & 155 & 70 \\
\hline 13 & Silica sand \#7 & $\begin{array}{c}\mathrm{R} 1+\mathrm{R} 2: 300+ \\
800\end{array}$ & Lifting & 1.60 & 1.32 & 155 & 55 \\
\hline 14 & Silica sand \#7 & $\begin{array}{c}\mathrm{R} 1+\mathrm{R} 2: 300+ \\
800\end{array}$ & Rainfall & 1.60 & 1.32 & 155 & 70 \\
\hline 15 & Silica sand \#7 & $\begin{array}{c}\mathrm{R} 1+\mathrm{R} 2: 300+ \\
800\end{array}$ & Lifting & 1.60 & 1.32 & 155 & 70 and 0 \\
\hline
\end{tabular}

Table 3. Small-scaled tests using tilt sensors with long rods.

\begin{tabular}{cccccccc}
\hline Test No. & Material & $\begin{array}{c}\text { Radius of the } \\
\text { Slip Surface } \\
(\mathbf{m m})\end{array}$ & $\begin{array}{c}\text { Triggering } \\
\text { Factor }\end{array}$ & $\begin{array}{c}\text { Base Layer } \\
\text { Density }\left(\mathrm{g} / \mathrm{cm}^{3}\right)\end{array}$ & $\begin{array}{c}\text { Surface Layer } \\
\text { Density }\left(\mathrm{g} / \mathrm{cm}^{3}\right)\end{array}$ & $\begin{array}{c}\text { Depth } \\
(\mathbf{m m})\end{array}$ & $\begin{array}{c}\text { Rod Lengths } \\
(\mathbf{m m})\end{array}$ \\
\hline 16 & Silica sand \#7 & $\begin{array}{c}\text { R1 + R2: } 300+ \\
800\end{array}$ & Lifting & 1.60 & 1.32 & 155 & 180 \\
17 & Silica sand \#7 & $\begin{array}{c}\text { R1 + R2: } 300+ \\
800\end{array}$ & Rainfall & 1.60 & 1.32 & 155 & 180 \\
\hline
\end{tabular}

\subsubsection{Small-Scaled Model Tests Using Tilt Sensors without Rods}

The specific testing conditions, including the geometries of the predefined slip surfaces, the materials used in the model tests and their densities and landslide-triggering factors, are listed in Table 1. The schematic illustration of the cross sections of the slope models and the arrangements of the apparatuses employed in these tests are presented in Figure 4. As shown in Figure 4, tilt sensors were installed on the slope, and an external tilt sensor was attached to the container. As illustrated in Table 1, in Tests 1-7 and Test 10, slope sliding was triggered by inclining the wooden container step-by-step, while artificial rainfall was applied in Test 8 and Test 9 to induce sliding.

\subsubsection{Small-Scaled Model Tests Using Tilt Sensors with Short Rods}

Model tests using tilt sensors with short rods installed above the predefined slip surface were conducted to investigate the tilting direction of the tilt sensors installed on slopes. The details about the geometries of the predefined slip surfaces, the materials used in the model tests and their densities and landslide-triggering factors are listed in Table 2. The schematic illustration for the cross sections of the slope models and the arrangements of the apparatuses employed in these tests are presented in Figure 5.

\subsubsection{Small-Scaled Model Tests Using Tilt Sensors with Long Rods Reaching the Slip Surface}

Two model tests were designed to investigate the tilting behaviors of sensors with long rods when landslides are triggered by changes in the stress field through lifting the model test box and changes in the water content induced by simulated rainfall. The geometry of the predefined slip surface and details of the materials used in these tests, as well as the landslide-triggering factors, are listed in Table 3. The schematic illustration for the cross sections of the slope models and the arrangements of the apparatuses employed in these tests are presented in Figure 6.

\subsection{Field Tests}

The site for the field tests, which consists of weak expansive soil and some plant roots, is located in Guangxi Province, and the slope angle is 43 degrees. Trenches were excavated both at the toe and the crest of this slope to a depth of $0.4 \mathrm{~m}$. Rainfall was supplied by an artificial rainfall supply system consisting of a pump, artificial pond, water separator and nozzles. In Field Test 1, the rainfall intensity was set to $40 \mathrm{~mm} / \mathrm{min}$. Tilt sensors with different lengths of rods, $50 \mathrm{~mm}, 300 \mathrm{~mm}$ and 
$800 \mathrm{~mm}$, were installed on the slope. The arrangement of the sensors and geometries of the slopes are shown in Figures 7a and 8a. The rainfall intensity in Field Test 2 was $21 \mathrm{~mm} / \mathrm{h}$, lower than that in Field Test 1. There were two types of rods with different lengths in Field Test 2, $30 \mathrm{~mm}$ and $300 \mathrm{~mm}$. The arrangement of the sensors and geometry of the slope are different in Field Test 2, as shown in Figures $7 \mathrm{~b}$ and $8 \mathrm{~b}$.

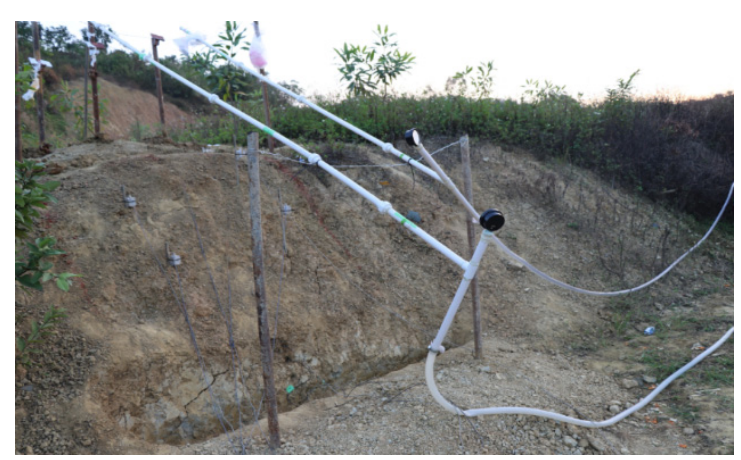

(a)

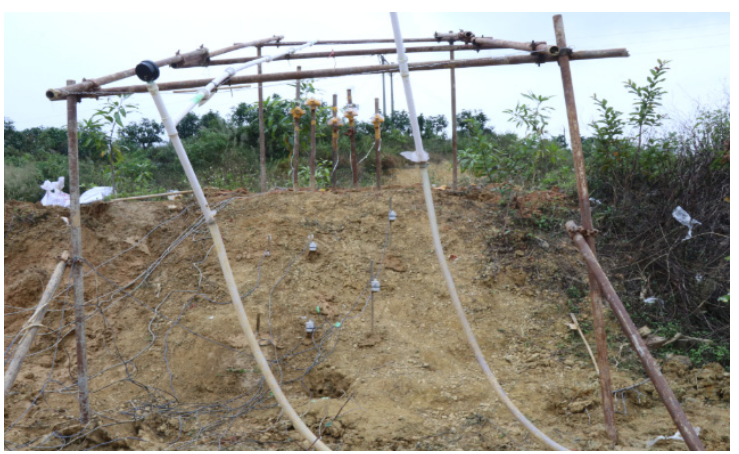

(b)

Figure 7. Images for (a) Field Test 1 and (b) Field Test 2.

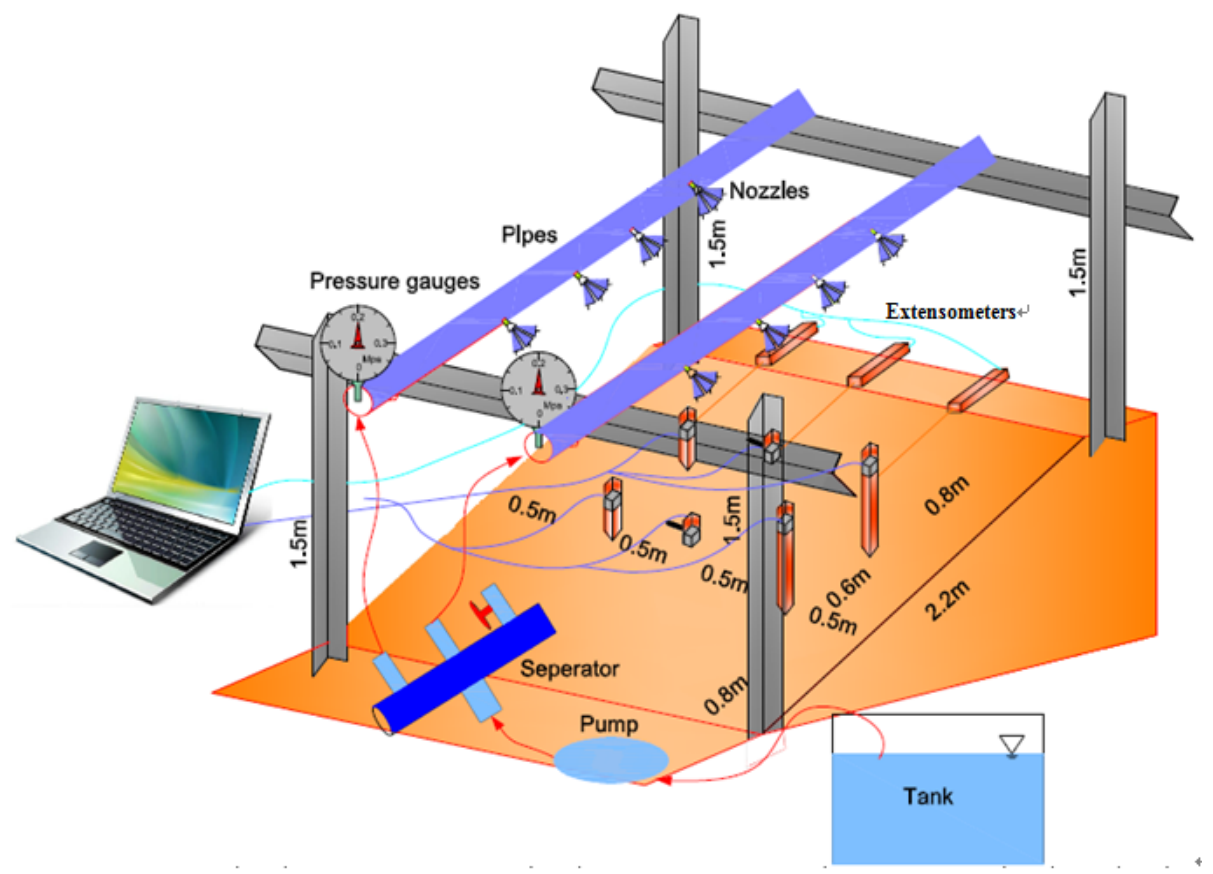

(a)

Figure 8. Cont. 


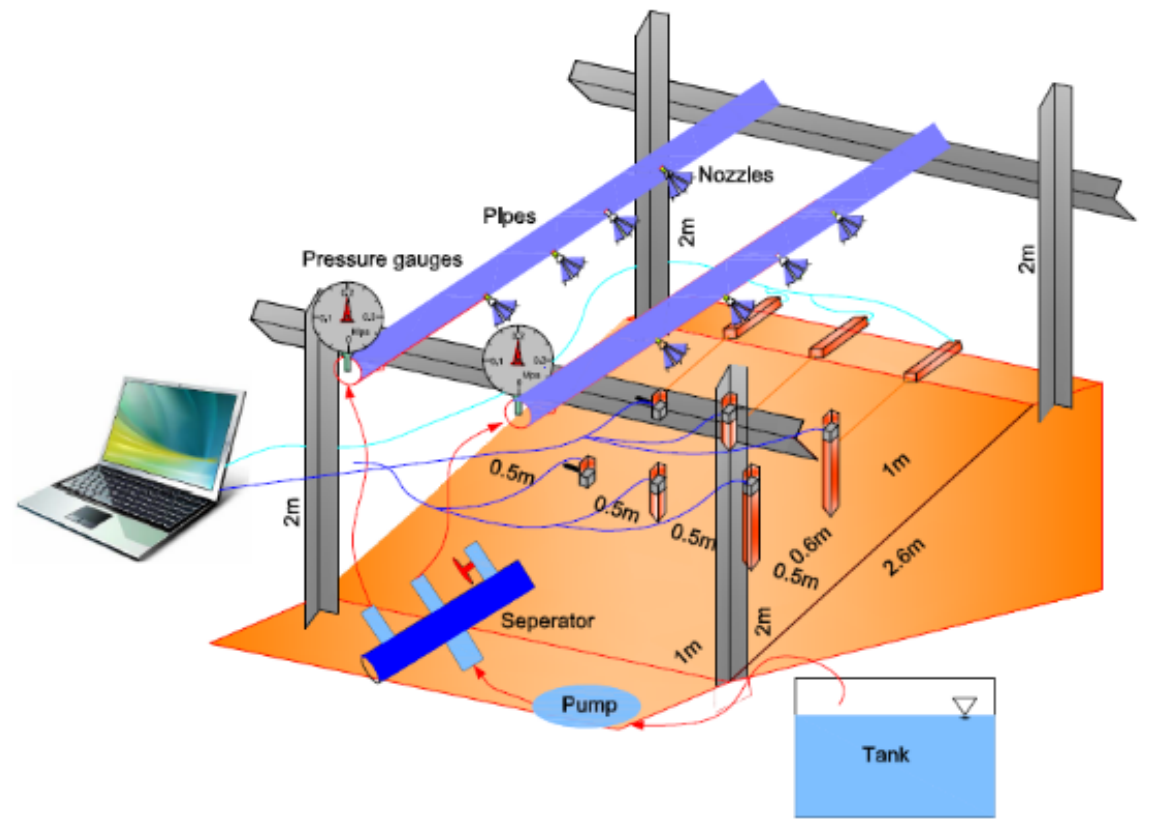

(b)

Figure 8. Illustration of the arrangement of the sensors in (a) Field Test 1 and (b) Field Test 2.

\section{Results and Discussion}

\subsection{Model Tests}

\subsubsection{Small-Scale Model Tests Using Tilt Sensors without Rods}

The landslides in Tests $1-8$ were caused by inclining the wooden container step-by-step, and the landslip in Tests 9 and 10 was caused by artificial rainfall. The difference between the data obtained from the tilt sensor installed in the surface layer and that from the external tilt sensor attached to the edge of the container represents the tilting angle induced by slope sliding, as shown in Figure 9. As illustrated in Figure 9, the tilt sensors without rods show the same rotation trend as the landslide mass regardless of the varying test conditions. To a certain extent, the behavior of the tilt sensor without rods represents the behavior of the soil in a landslide mass because the tilt sensors are embedded in the soil and small enough to ignore their effect on the soil properties. However, there exists an exception in Test 3, as shown in Figure 9c. The tilt sensor marked as T3 shows an abnormal tilting behavior compared to the other tilt sensors because of the slope rupture at the bottom part of the slope model caused the uncertainty behavior of the tilt sensor, as shown in Figure 4c. Thus, the data from the tilt sensor T3 dropped suddenly. As illustrated in the data collected, the tilting angle of the sensors shows an abrupt increasing trend as the landslide developed, and the position of the tilt sensors and the landslide-triggering factors do not affect the trend in the change in tilting angle obtained by the tilt sensors. 


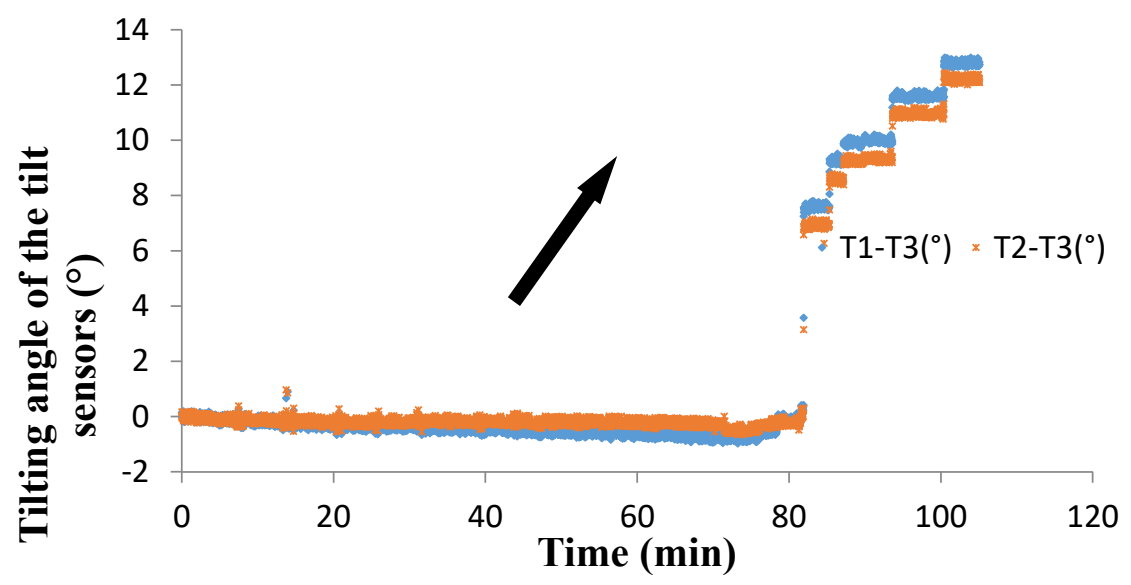

(a)

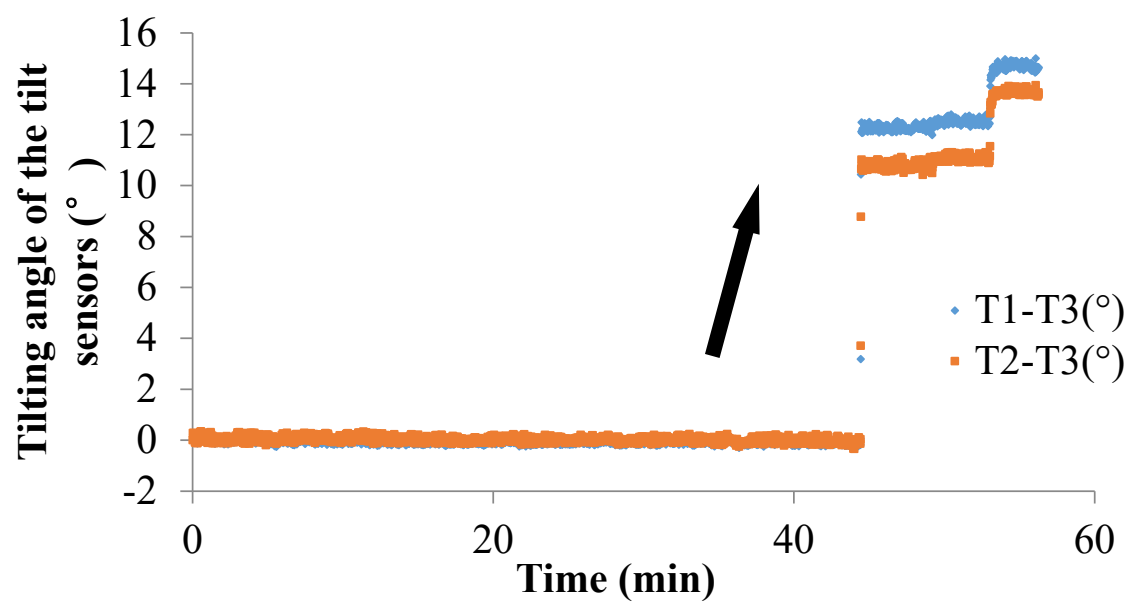

(b)

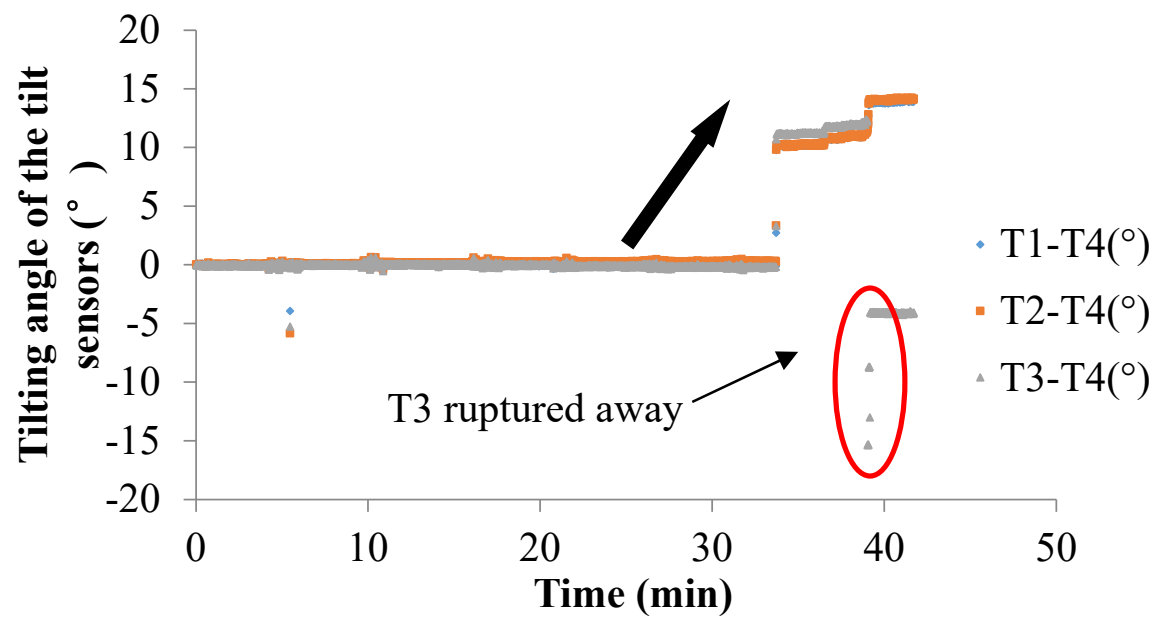

(c)

Figure 9. Cont. 


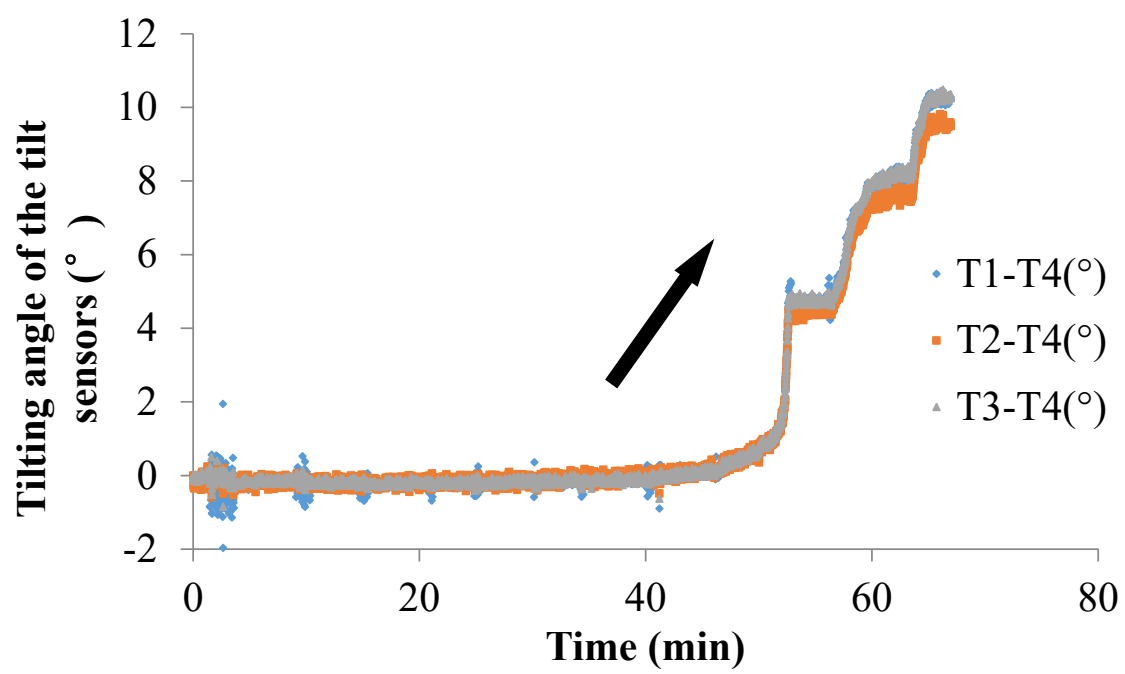

(d)

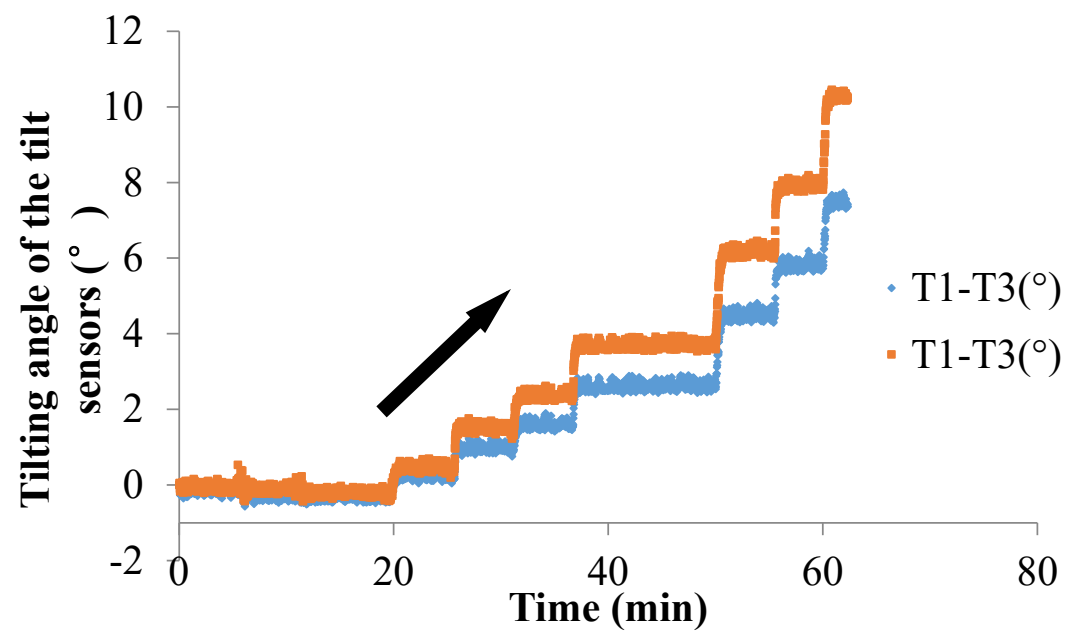

(e)

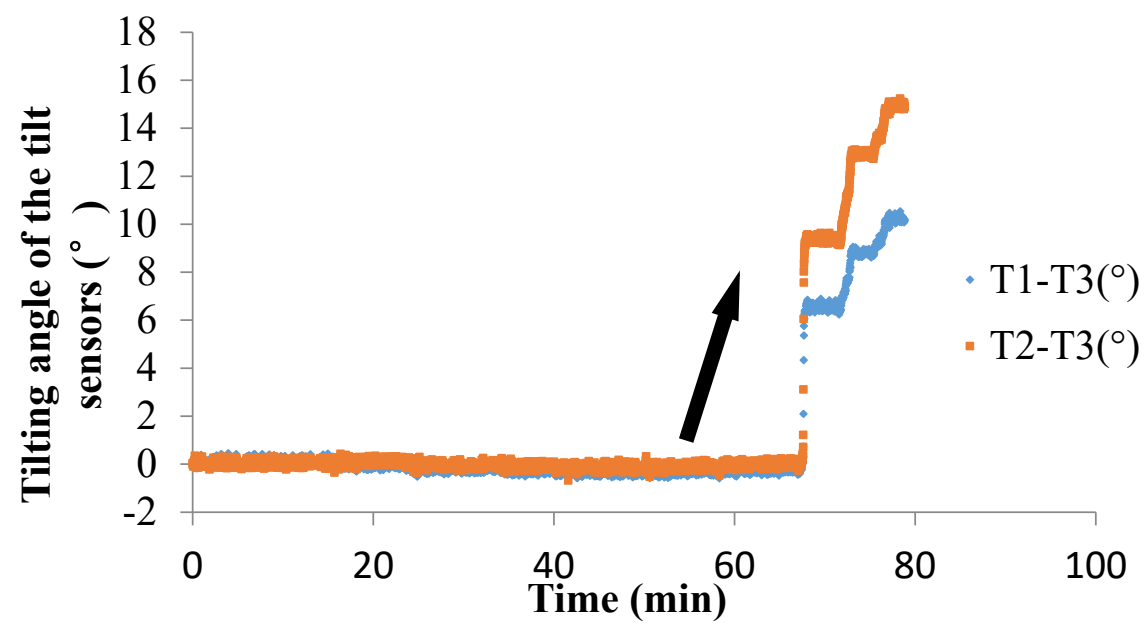

(f)

Figure 9. Cont. 


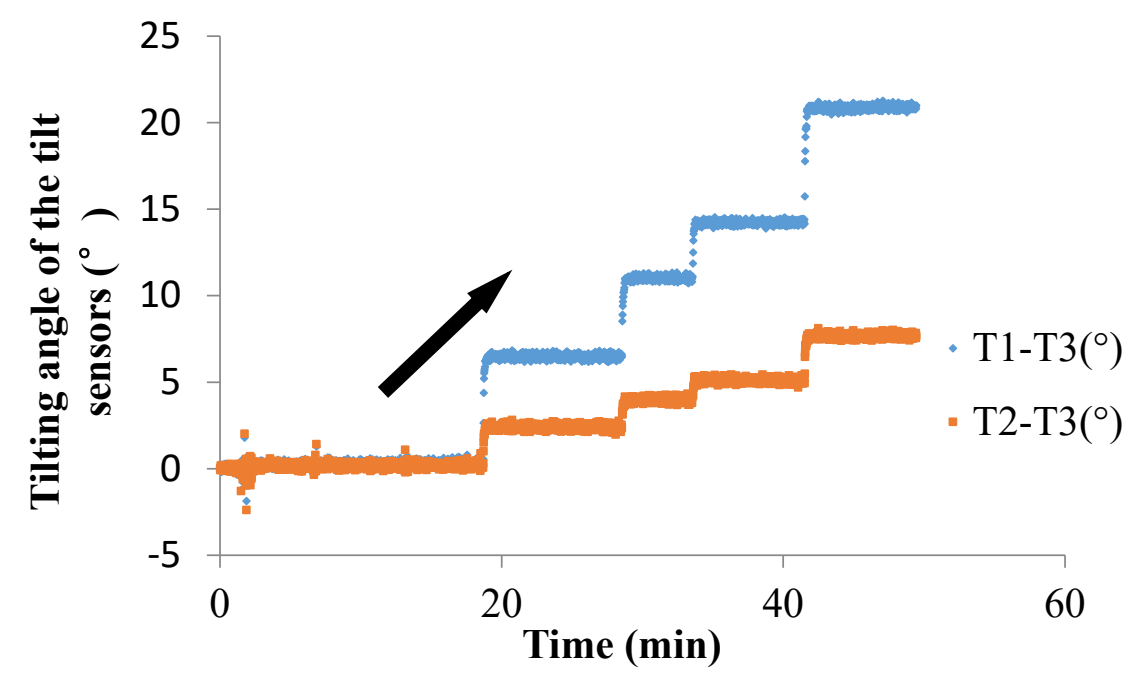

(g)

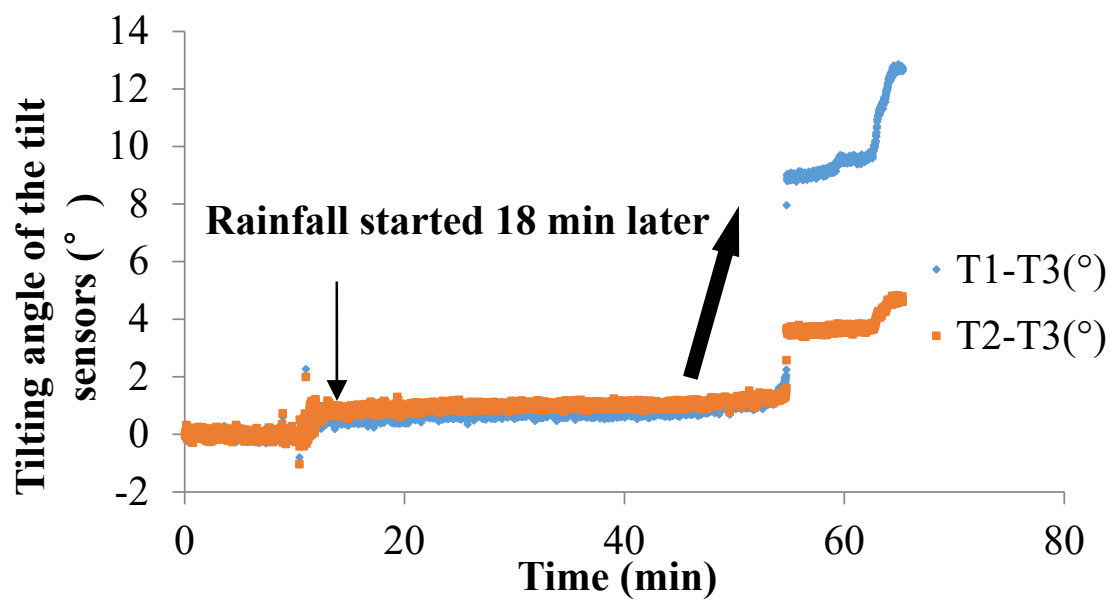

(h)

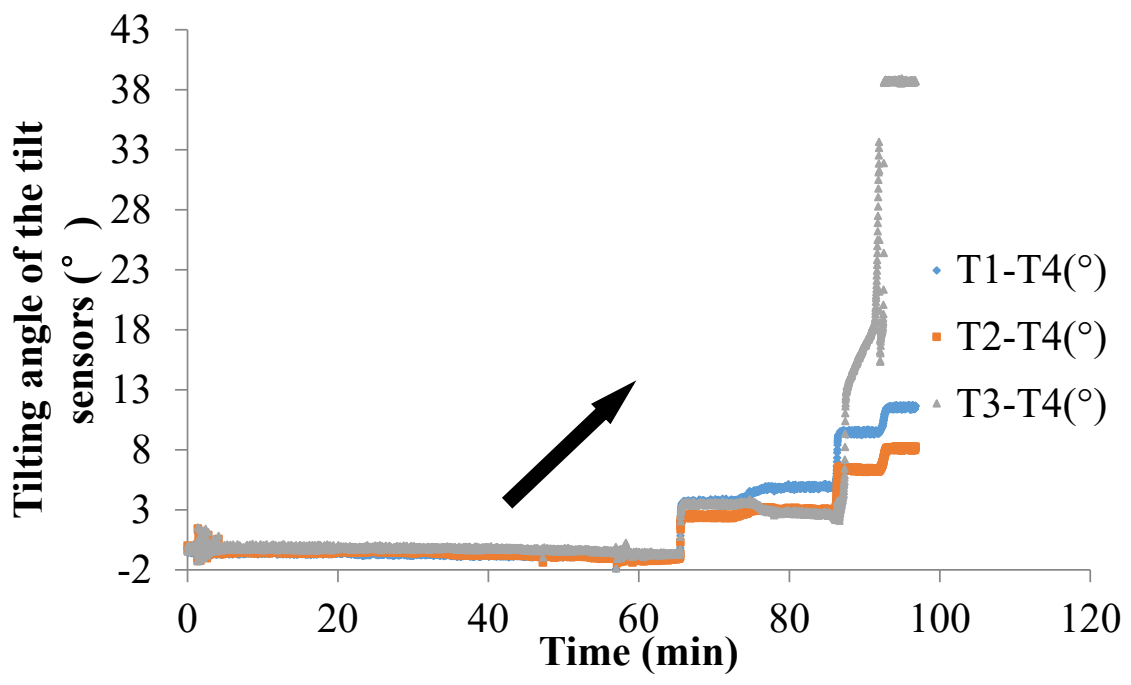

(i)

Figure 9. Cont. 


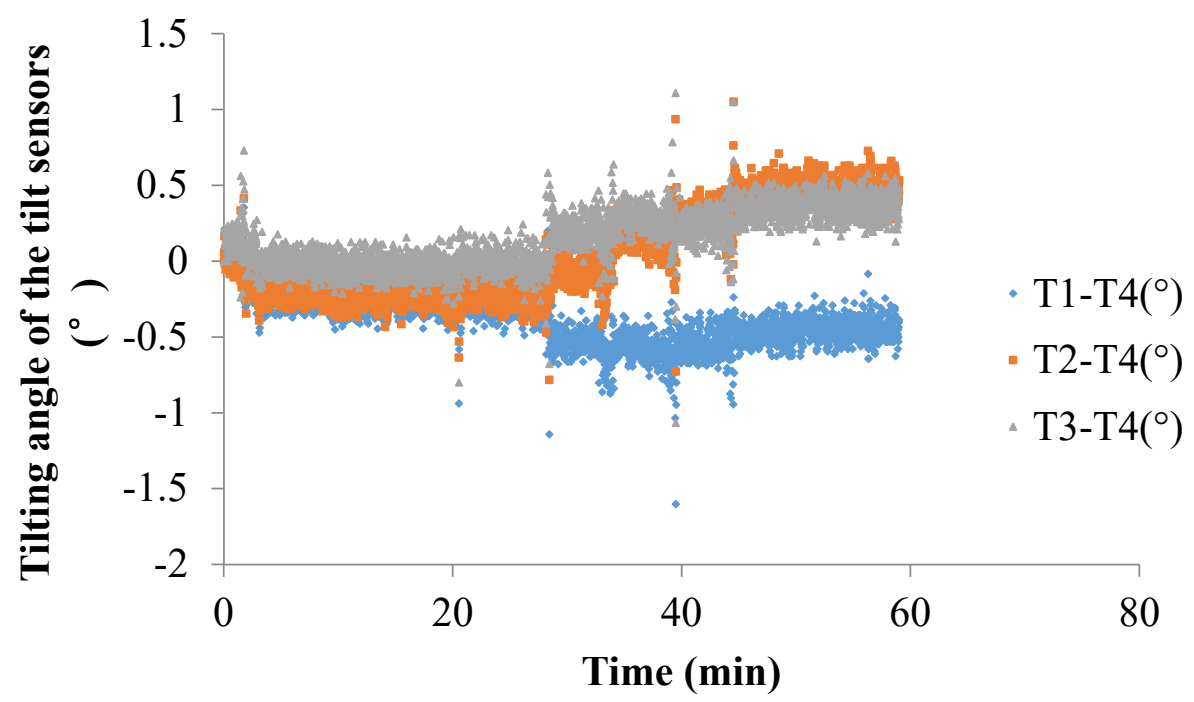

(j)

Figure 9. Temporal history of the slope-tilting degree recorded in Test 1 to Test 10 as shown from (a) to $(\mathbf{j})$.

In Test 10, the changing tilting angle of the sensor is not obvious in the translational landslide, but the tilt sensor near the edge of the slope shows a different rotating direction compared to the other two tilt sensors. This phenomenon is caused by the complex behavior of the soil when the slope collapses, especially when the soil is near the edge of the slope. Thus, the tilting behavior of the tilt sensor of a translational landslide is uncertain.

\subsubsection{Small-Scale Model Tests Using Tilt Sensors with Short Rods}

The data of the temporal history of the tilting angle obtained by the tilt sensors in Tests 11-15 are plotted in Figure 10. As Figure 10 illustrates, the tilt sensors with the short rods show the same rotation trend as the landslide masses, which was not affected by the trigger factor, radius of the slip surface, relative density or type of soil. This tilting behavior of the tilt sensors with the short rods is the same as that of the tilt sensors without the rods mentioned above, and the tilting angle of the sensors also shows an abrupt increasing trend as the landslide developed. The position of the tilt sensors and the landslide-triggering factors also do not affect the trend in the change in the tilting angle obtained by the tilt sensors, as shown in the temporal history of the slope-tilting experiments.

Five tilt sensors were used in Test 15 . The tilt sensor marked as T5 was attached to the wooden container to measure its tilting angle. The tilt sensors marked as T1 and T2 with $70 \mathrm{~mm}$ short rods were installed in the top part and bottom part of the slope. Additionally, the tilt sensors marked as T3 and T4 without rods were close to the locations of T1 and T2, respectively, as illustrated in Figure $5 \mathrm{f}$. Based on the regression analysis, there is an approximate linear relationship between the tilt angle of the tilt sensors with short rods (T1 and T2) and that of the tilt sensors without rods (T3 and T4), as shown in Figure 11. The relationship between T1 and T3 can be expressed as $y=0.9715 x-0.2507$, and the relationship between T1 and T3 can be expressed as $\mathrm{y}=1.0285 \mathrm{x}-0.6422$, as plotted in Figure 6 . In these two equations, $x$ denotes the tilt angle of the tilt sensor with a short rod (T1 or T2), and $y$ denotes the tilt angle of the tilt sensor without a rod (T3 or T4). Tilt sensors with no rods or with short rods installed above the slip surface show a similar tilting behavior during slope sliding, as the two equations express, which means that the tilt sensors with short rods can reveal the tilt behavior of soil in a landslide mass, and that the tilt sensors do not have to be embedded in the soil but can be attached to a rod that sticks into the soil as a more convenient way to install the tilt sensors. 


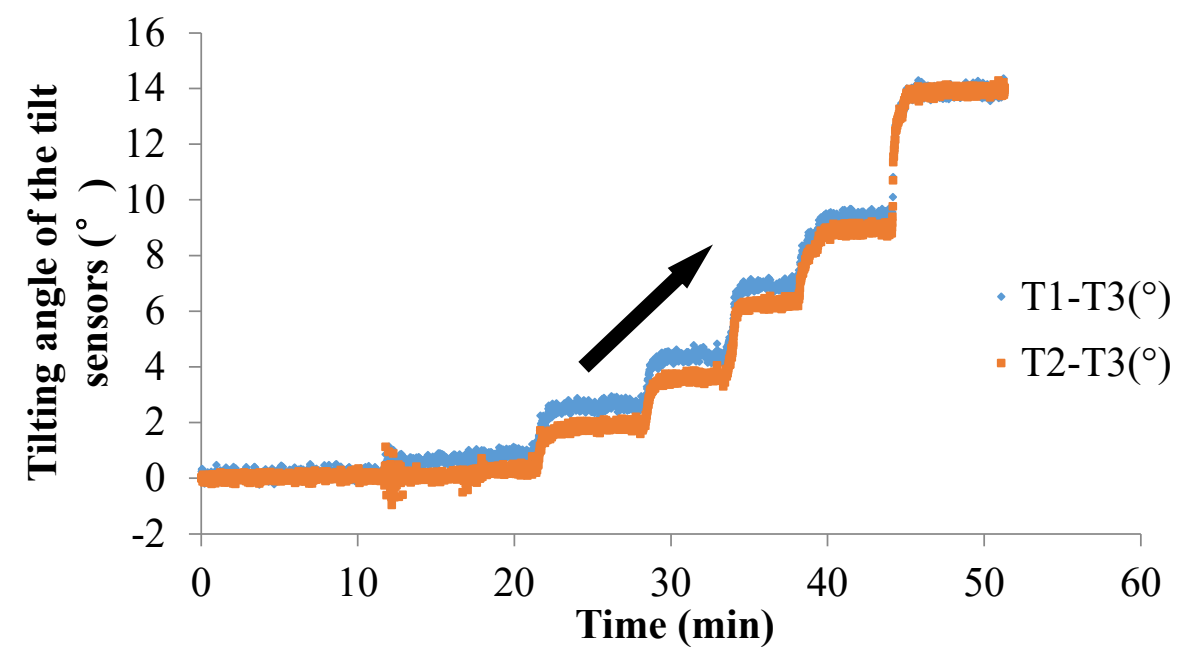

(a)

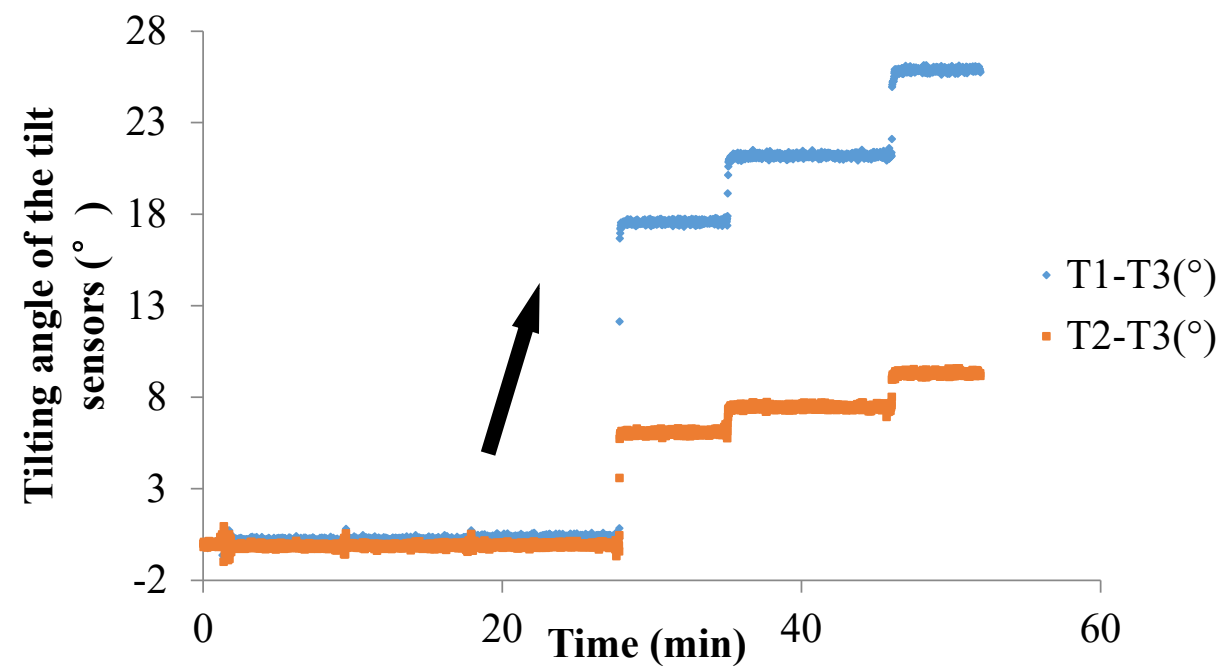

(b)

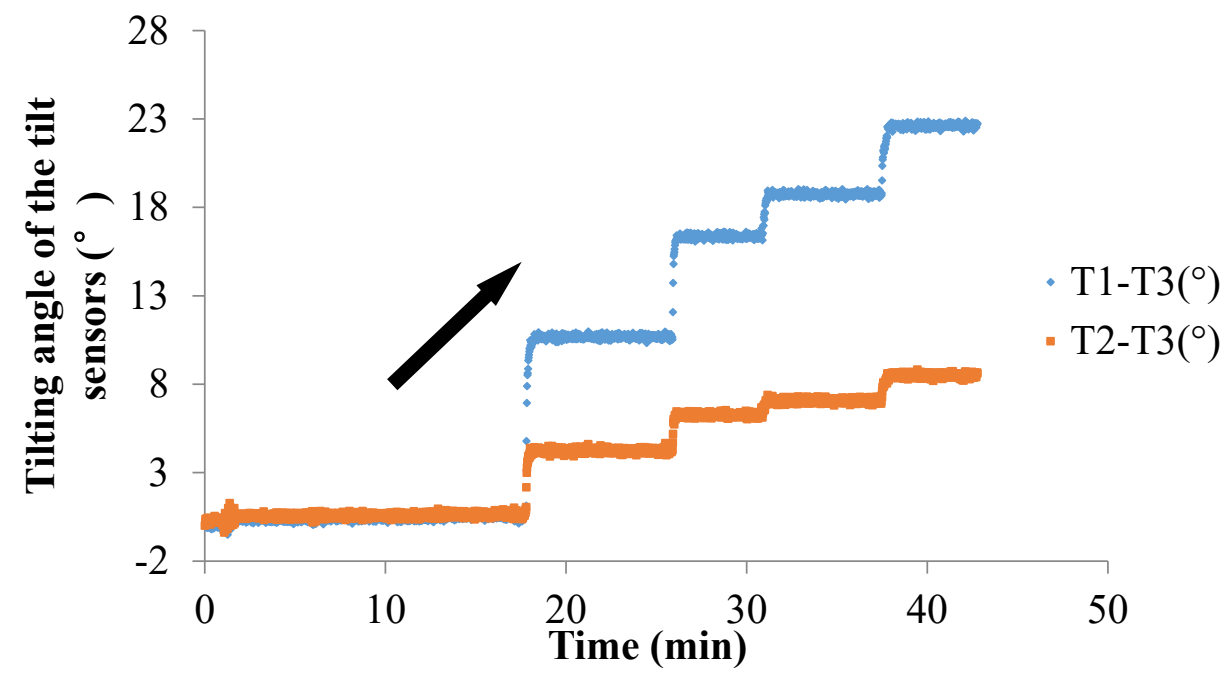

(c)

Figure 10. Cont. 


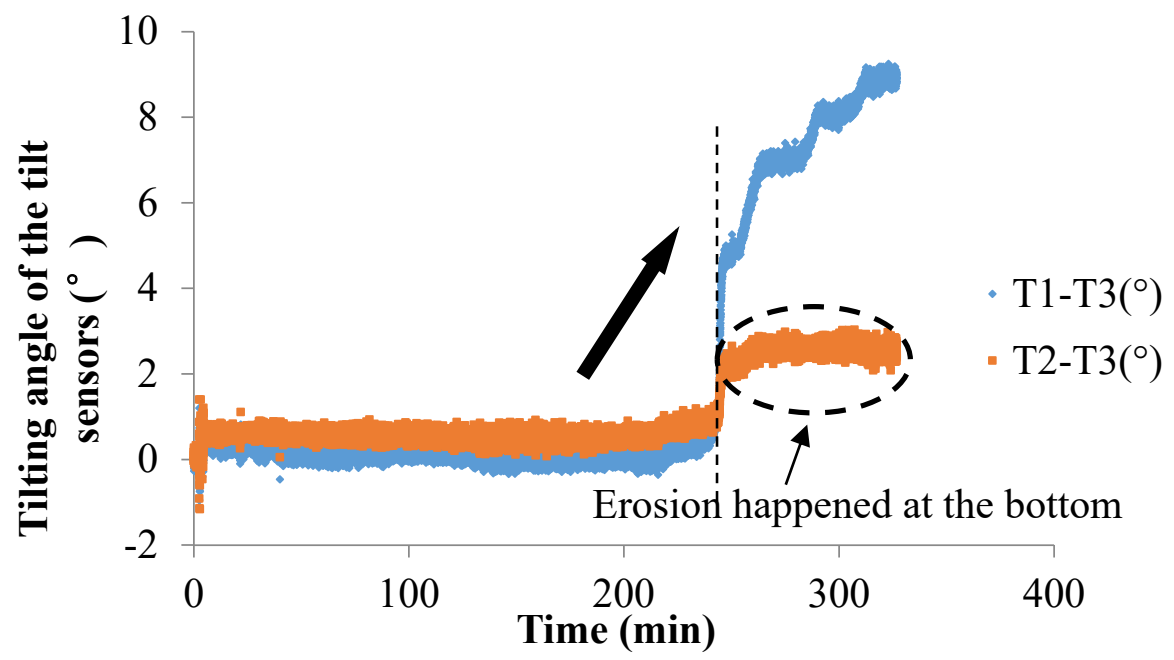

(d)

Figure 10. Temporal history of the slope-tilting degree recorded in Test 14 . Test 11 to Test 14 as shown from (a) to (d).

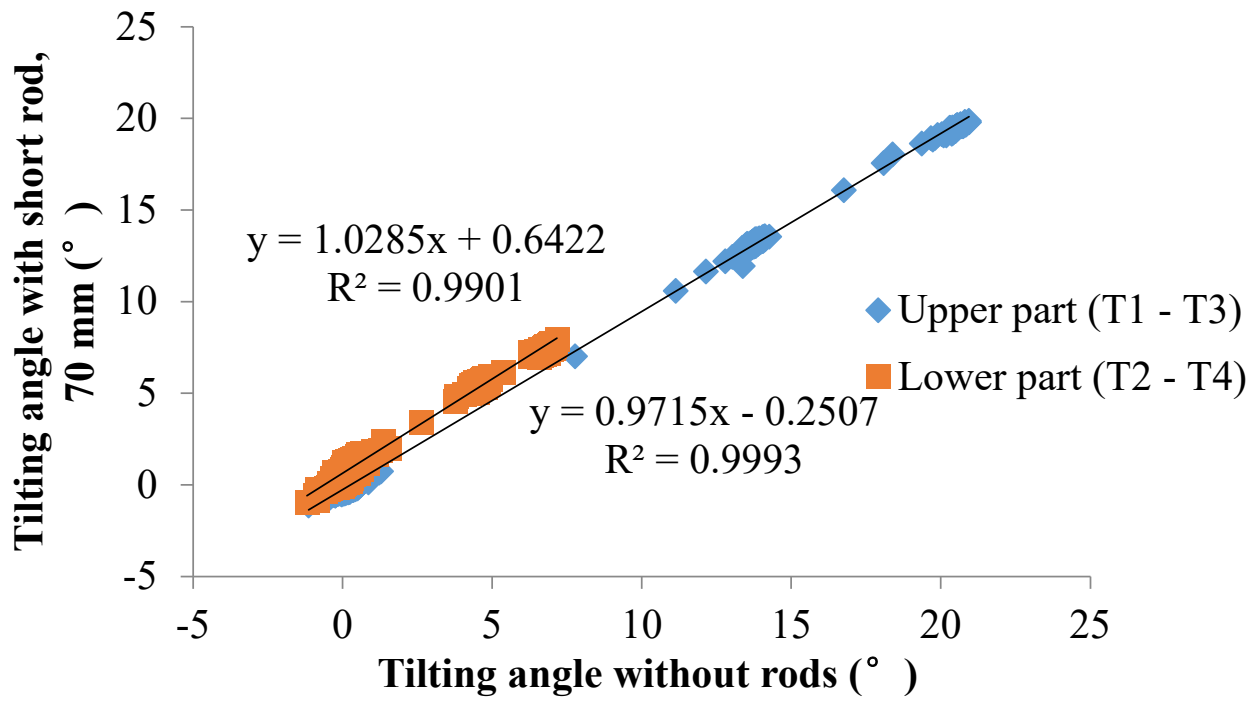

Figure 11. The relationship between the tilt angle measured by sensors without rods and sensors with short rods in Test 15.

\subsubsection{Small-Scale Model Tests Using Tilt Sensors with Long Rods Reaching the Slip Surface}

The results of the temporal history of the tilting angle plotted in Figure 12 show that, regardless of the landslide-triggering factor, the sensors with long rods have an opposite rotational trend with the landslide masses when landslides occur. Because part of the rod is in the sliding mass, the lower part of the rod is embedded in the soil that does not move, and the upper part of the rod moves forward with the landslide mass, which leads to the rod tilting forward, which was observed in these two small-scale model tests. This behavior is also observed by Xie et al. [42], who found that the tilt sensor located above the slip surface of the landslide with rotational components tilted backward when the slope was sliding, while the tilt sensor together with a rod reaching the slip surface of slopes tilted forward in the failure process. In this study, the results show that the tilt direction of the rods is not affected by the landslide-triggering factors and other soil parameters considered in the model test but is determined by the position of the rod related to the slip surface. In addition, the tilting angle of the sensors also shows an abrupt increasing trend as the landslide develops. Moreover, the position of the 
tilt sensors and the landslide-triggering factors do not affect the trend in the change in the tilting angle. However, the tilt directions of the tilt sensors are different than those of the tilt sensors without rods or with short rods.

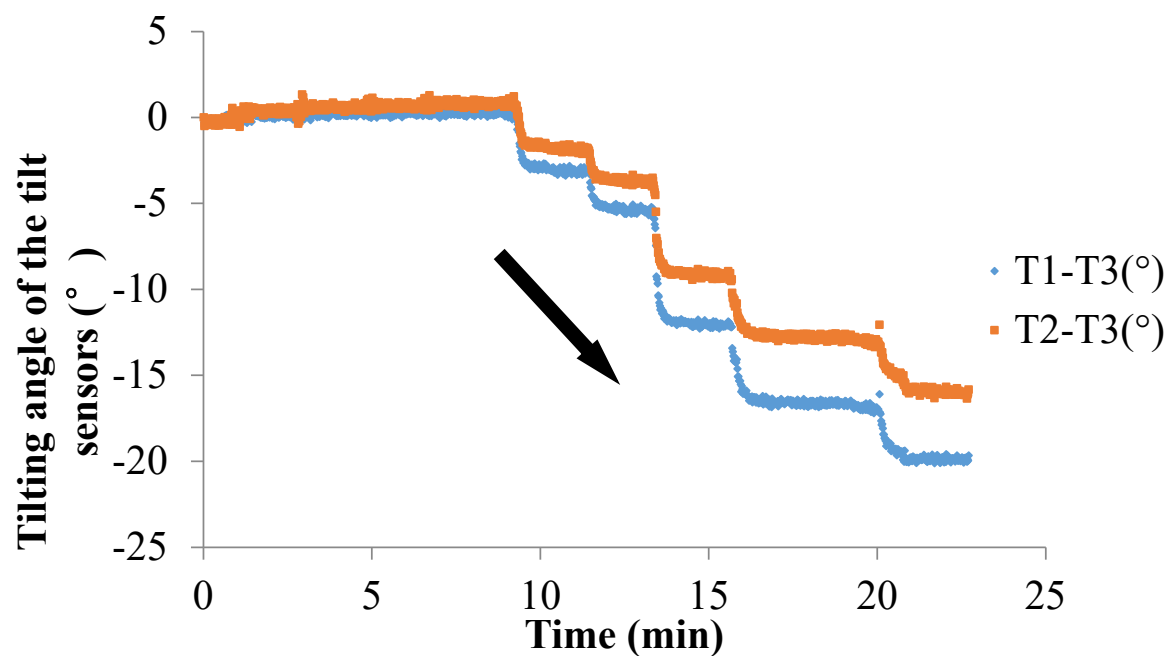

(a)

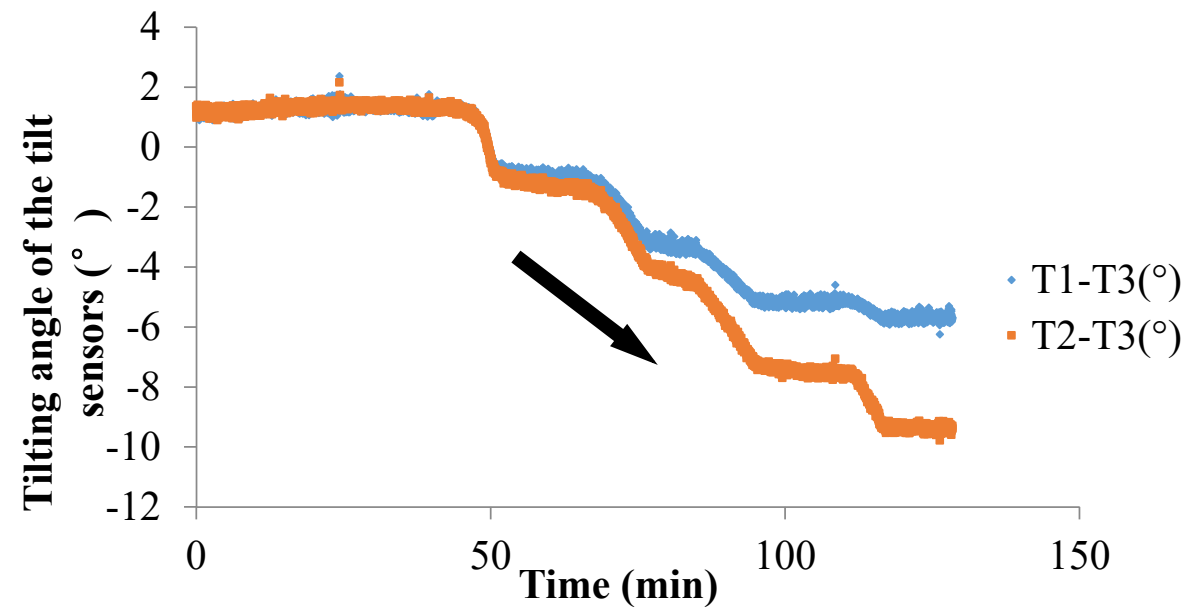

(b)

Figure 12. Temporal history of the slope-tilting degree recorded in (a) Test 16 and (b) Test 17.

\subsection{Field Tests}

In Field Test 1, major deformation occurs in the top part of the slope with a steep scarp angle, as shown in Figure 13a. The depth of the slip surface of this slope is approximately $250 \mathrm{~mm}$, which is deeper than the location of the failed tilt sensor. Consequently, the tilt sensor located in the failed area tilted backward, as presented in Figure 14a. This result is consistent with that of the model tests. In Field Test 2, the failure of the tilt sensors with rods of different lengths, $50 \mathrm{~mm}$ and $300 \mathrm{~mm}$, installed in the lower part of the slope was caused by erosion, as shown in Figure 13b. Major deformation occurs in the top part of the slope, and the depth of the slip surface is also approximately $250 \mathrm{~mm}$. As a result, the tilt sensor attached to a short rod, approximately $50 \mathrm{~mm}$, tilted backward, as presented in Figure 14b, while the tilt sensor attached to a longer rod, approximately $300 \mathrm{~mm}$, tilted forward, as shown in Figure 15; the length of the long rod is greater than $250 \mathrm{~mm}$, the depth of the slip surface. This result is also consistent with the analysis of the results obtained from the model tests. The tilting angle of the sensors also shows an abrupt increasing trend as landslides develop, which can also be 
observed from the model test. In general, these test results, obtained from the model and field tests, can reveal that the abnormal tilting in the slope surface is a precursor of slope failure.

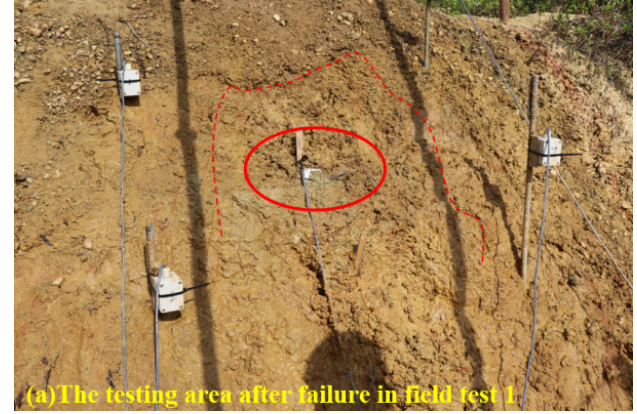

(a)

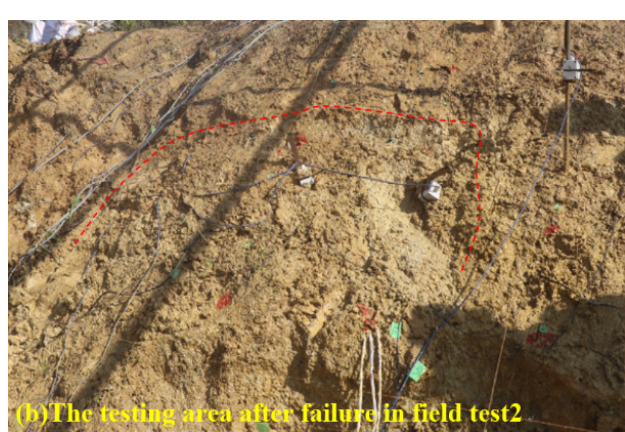

(b)

Figure 13. Images of the testing area before and after slope failure: (a) the testing area after failure in Field Test $1 ;(\mathbf{b})$ the testing area after failure in Field Test 2.

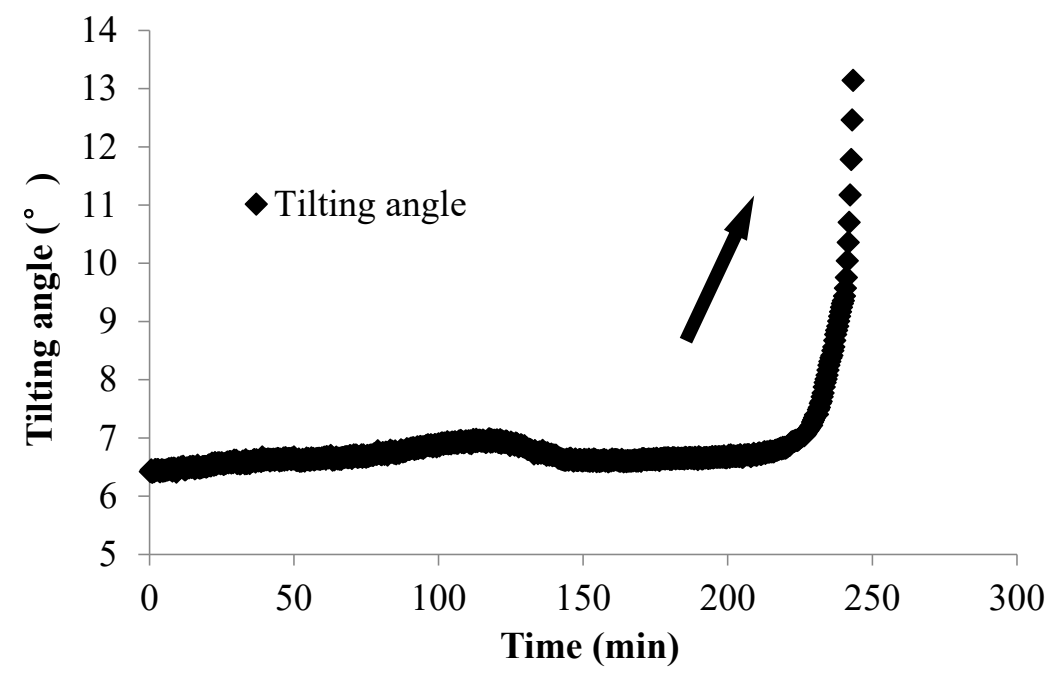

(a)

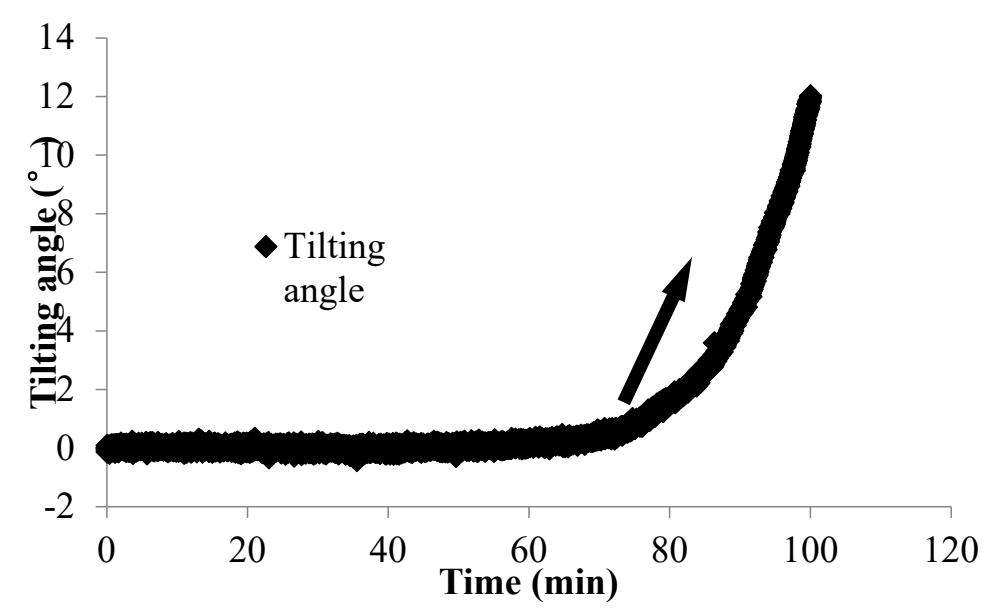

(b)

Figure 14. Temporal history of the slope-tilting degree recorded by a tilt sensor with a rod $50 \mathrm{~mm}$ long located in the failed area in (a) Field Test 1 and (b) Field Test 2. 


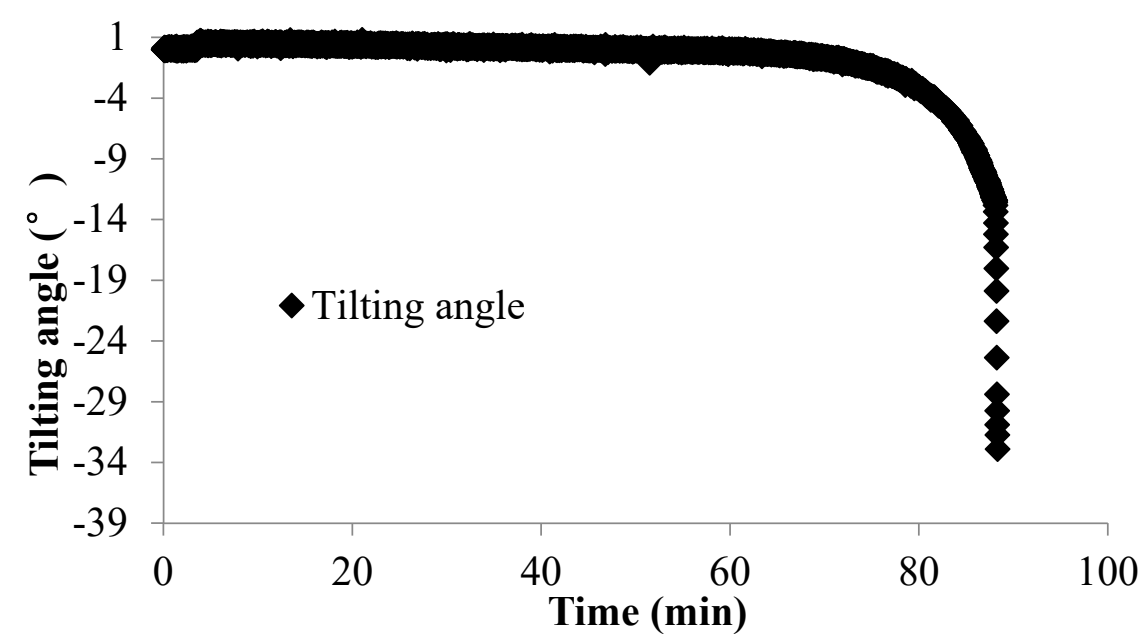

Figure 15. Temporal history of the slope-tilting degree recorded by the tilt sensor with a rod $300 \mathrm{~mm}$ long located in the failed area of the slope in Field Test 2.

\subsection{Discussion}

Surface tilting was tentatively considered an implication for the prediction of landslides with rotational components $[26,44]$. From the authors' previous study, the tilting rate also shows a sharp increase at a shorter duration before slope failure [39-43]. In this study, a sharp increase in the tilting rate of tilt sensors before landslides is also observed, as shown in Figures 9, 10, 12, 14 and 15. Therefore, this study suggests that tilt behavior is an effective index to predict and monitor landslides.

Longstanding efforts have been made to predict the slip surface of slopes, and some methods have been proposed in recent decades based on surface displacements and morphology [45-49]. The computational process of those methods is complicated and involves many assumptions [49]. The authors' previous study [43] revealed that the surface deformation due to the landslide masses is mainly caused by the slope rotation against the centers of the slip surfaces when the slope slides, and the path of the sliding masses is parallel to the slip surfaces. A method has also been proposed for the prediction of the slip surface, but this method does not consider the occurrence of different tilting directions by the tilt sensors, which has been observed but not previously investigated [42].

Based on the results of the model tests and field tests in this study, the tilting direction of the tilt sensors with long rods shows an opposite rotational trend with the landslide mass because if the lower part of the rod inserts into the stable part of the soil below the slip surface, the part of the rod in the landslide mass moves forward with the soil when a landslide occurs. Hence, tilt sensors with short rods may also show an opposite rotational trend with the landslide mass if part of the rod is inserted into the stable part of the soil below the slip surface. Thus, the depth of installation of the tilt sensors with rods should be wisely chosen for different types of landslides. For landslides with curved slip surfaces, both tilt sensors with short rods and tilt sensors with long rods can be used. For shallow translational landslides, tilt sensors with short rods are not effective. The rod of the tilt sensor needs to be inserted into the stable layer for monitoring these types of landslides, but further investigation is needed.

\subsection{Limitations and Future Scope}

Considering that a complex curve can decompose into different arcs with different radii for simplification, the slip surface in the model tests is assumed to be semicircular or is assumed to have two quadrants with different radii. However, in reality, the slide beds of the landslides also have types of lines and complex curves. The data in Test 10 of this study show that the tilt sensors are not suitable for monitoring translational landslides. 
Hence, the proposed prediction method still has some drawbacks and limitations. First, further studies are needed to investigate the landslides of complex slide beds. Secondly, a detailed comparison with other technologies was not considered here and needs further investigation. Thirdly, this early warning system should be improved for monitoring translational landslides, and further studies are needed.

\section{Conclusions}

In this paper, the tilting direction of the tilt sensors attached to rods of different lengths installed on the surface of slopes was investigated by performing a series of model tests and field tests. The effects of different parameters on the tilting direction of the sensors were also investigated. The results revealed that the tilting angle of the tilt sensors with no rods and that of the tilt sensors with short rods show an approximate linear relationship during slope sliding. The tilting rate tended to increase, and a shorter duration remained before failure. This finding suggests that the tilt behavior is an effective index to predict and monitor landslides. However, the tilting direction of the tilt sensors with long rods shows an opposite rotational trend with the landslide mass because if the lower part of the rod is inserted into the stable part of the soil below the slip surface, the part of the rod in the landslide mass moves forward with the soil when a landslide occurs. The tilt sensors with long rods show a forward movement trend.

Hence, a tilt sensor with a long rod can be applied to monitor shallow translational landslides, but the end of the rod must be inserted into the stable layer; this still needs further investigation. A tilt sensor without rods and a tilt sensor with short rods can be applied to monitor shallow and rotational landslides. Both tilt sensors with short rods and tilt sensors with long rods can be used in landslides with curved slip surfaces, but tilt sensors with short rods are not effective in translational landslides.

In general, the results and previous studies prove that the early warning system the authors have proposed, or similar systems, can be effective, inexpensive and convenient to install to mitigate the losses caused by landslides. However, further studies and investigations are needed to perfect these types of systems, because the mechanism behind the sensors with rods rotating with the landslide mass is still unclear, and more data are needed to make the system adapt to complex situations that may occur in applications.

Author Contributions: Conceptualization, T.U. and J.X.; methodology, J.X.; validation, C.F., P.Y., and J.T.; formal analysis, S.Q.; investigation, L.W.; resources, T.U.; data curation, J.T.; writing—original draft preparation, S.Q.; writing - review and editing, S.Q.; visualization, J.X.; supervision, Q.S.; project administration, J.X.; funding acquisition, J.X. All authors have read and agreed to the published version of the manuscript.

Funding: This research was supported by Chinese Scholarship Council (CSC, corresponding author, grant no. 201506370052) and the Grants-in-Aid for Scientific Research of the Japan Society for the Promotion of Science (JSPS), Core-to-Core Program B (no. 16H04407).

Conflicts of Interest: The authors declare no conflicts of interest.

\section{References}

1. Keefer, D.K.; Wilson, R.C.; Mark, R.K.; Brabb, M.E.; Brown, W.M., III; Ellen, S.D.; Harp, E.L.; Wieczorek, G.F.; Alger, C.S.; Zatkin, R.S. Real-time landslide warning during heavy rainfall. Science 1987, 238, 921-925. [CrossRef]

2. Okada, K. Soil Water Index Sokko-Jiho; Japan Meteorological Agency: Tokyo, Japan, 2001; pp. 69-567.

3. Kuramoto, K.; Noro, T.; Osanai, N.; Kobayashi, M.; Okada, K. A study on rainfall indexes for giving early warning information for sediment-related disasters. In Proceedings of the Annual Research Meeting, Minneapolis, MN, USA, 12 June 2005; pp. 186-187.

4. Osanai, N.; Shimizu, T.; Kuramoto, K.; Kojima, S.; Noro, T. Japanese early-warning for debris flows and slope failures using rainfall indices with Radial Basis Function Network. Landslides 2010, 7, 325-338. [CrossRef]

5. Ishihara, Y.; Kobatake, S. Runoff Model for Flood Forecasting. Available online: https://core.ac.uk/reader/ 39254740 (accessed on 28 April 2020). 
6. Dixon, N.; Smith, A.; Flint, J.A.; Khanna, R.; Clark, B.; Andjelkovic, M. An acoustic emission landslide early warning system for communities in low-income and middle-income countries. Landslides 2018, 15, 1631-1644. [CrossRef]

7. Deng, L.; Yuan, H.; Chen, J.; Sun, Z.; Fu, M.; Zhou, Y.; Yan, S.; Zhang, Z.; Chen, T. Experimental investigation on progressive deformation of soil slope using acoustic emission monitoring. Eng. Geol. 2019, 261, 105295. [CrossRef]

8. Koerner, R.M.; McCabe, W.M.; Lord, A.E. Acoustic emission behavior and monitoring of soils. In Acoustic Emissions in Geotechnical Engineering Practice; ASTM International: West Conshohocken, PA, USA, 1981.

9. Rouse, C.; Styles, P.; Wilson, S.A. Microseismic emissions from flowslide-type movements in South Wales. Eng. Geol. 1991, 31, 91-110. [CrossRef]

10. Smith, A.; Dixon, N.; Meldrum, P.; Haslam, E.; Chambers, J. Acoustic emission monitoring of a soil slope: Comparisons with continuous deformation measurements. Geotech. Lett. 2014, 4, 255-261. [CrossRef]

11. Chen, Y.; Irfan, M.; Uchimura, T.; Cheng, G.; Nie, W. Elastic wave velocity monitoring as an emerging technique for rainfall-induced landslide prediction. Landslides 2018, 15, 1155-1172. [CrossRef]

12. Angeli, M.G.; Pasuto, A.; Silvano, S. A critical review of landslide monitoring experiences. Eng. Geol. 2000, 55, 133-147. [CrossRef]

13. Intrieri, E.; Gigli, G.; Mugnai, F.; Fanti, R.; Casagli, N. Design and implementation of a landslide early warning system. Eng. Geol. 2012, 147, 124-136. [CrossRef]

14. Carlà, T.; Intrieri, E.; Di Traglia, F.; Nolesini, T.; Gigli, G.; Casagli, N. Guidelines on the use of inverse velocity method as a tool for setting alarm thresholds and forecasting landslides and structure collapses. Landslides 2017, 14, 517-534. [CrossRef]

15. Ferrigno, F.; Gigli, G.; Fanti, R.; Intrieri, E.; Casagli, N. GB-InSAR monitoring and observational method for landslide emergency management: The Montaguto earthflow (AV, Italy). Nat. Hazards Earth Syst. 2017, 17, 845-860. [CrossRef]

16. Kamai, T. Monitoring the process of ground failure in repeated landslides and associated stability assessments. Eng. Geol. 1998, 50, 71-84. [CrossRef]

17. Corominas, J.; Moya, J.; Lloret, A.; Gili, J.A.; Angeli, M.G.; Pasuto, A.; Silvano, S. Measurement of landslide displacements using a wire extensometer. Eng. Geol. 2000, 55, 149-166. [CrossRef]

18. Stiros, S.C.; Vichas, C.; Skourtis, C. Landslide monitoring based on geodetically derived distance changes. J. Surv. Eng. 2004, 130, 156-162. [CrossRef]

19. Petley, D.N.; Mantovani, F.; Bulmer, M.H.; Zannoni, A. The use of surface monitoring data for the interpretation of landslide movement patterns. Geomorphology 2005, 66, 133-147. [CrossRef]

20. Hu, X.; Zhang, M.; Sun, M.; Huang, K.; Song, Y. Deformation characteristics and failure mode of the Zhujiadian landslide in the Three Gorges Reservoir, China. B Eng. Geol. Environ. 2015, 74, 1-12. [CrossRef]

21. Chung, M.C.; Tan, C.H.; Chen, C.H. Local rainfall thresholds for forecasting landslide occurrence: Taipingshan landslide triggered by Typhoon Saola. Landslides 2017, 14, 19-33. [CrossRef]

22. Thapa, P.S.; Adhikari, B.R. Development of community-based landslide early warning system in the earthquake-affected areas of Nepal Himalaya. J. Mt. Sci. 2019, 16, 2701-2713. [CrossRef]

23. Saito, M. Forecasting time of slope failure by tertiary creep. In Proceedings of the 7 th International Conference on Soil Mechanics and Foundation Engineering, Mexico City, Mexico, 29 August 1969; pp. 677-683.

24. Saito, M. On application of creep curves to forecast the time of slope failure. Landslides 1987, $24,30-38$. [CrossRef]

25. Fukuzono, T. A new method for predicting the failure time of a slope. In Proceedings of the 4th International Conference and Field Workshop on Landslide, Tokyo, Japen, 23-31 August 1985.

26. Voight, B. A method for prediction of volcanic eruptions. Nature 1988, 332, 125-130. [CrossRef]

27. Voight, B. A relation to describe rate-dependent material failure. Science 1989, 243, 200-203. [CrossRef] [PubMed]

28. Petley, D.N.; Bulmer, M.H.; Murphy, W. Patterns of movement in rotational and translational landslides. Geology 2002, 30, 719-722. [CrossRef]

29. Uchimura, T.; Towhata, I.; Wang, L.; Nishie, S.; Yamaguchi, H.; Seko, I.; Qiao, J. Precaution and early warning of surface failure of slopes using tilt sensors. Soils Found. 2015, 55, 1086-1099. [CrossRef] 
30. Smethurst, J.A.; Smith, A.; Uhlemann, S.; Wooff, C.; Chambers, J.; Hughes, P.; Lenart, S.; Saroglou, H.; Springman, S.M.; Löfroth, H.; et al. Current and future role of instrumentation and monitoring in the performance of transport infrastructure slopes. Q. J. Eng. Geol. Hydrogeol. 2017, 50, 271-286. [CrossRef]

31. Ćmielewski, B.; Kontny, B.; Ćmielewski, K. Use of low-cost MEMS technology in early warning system against landslide threats. Acta Geodyn. Geomater. 2013, 10, 172. [CrossRef]

32. Tran, D.T.; Nguyen, D.C.; Tran, D.N.; Ta, D.T. Development of a rainfall-triggered landslide system using wireless accelerometer network. IJACT 2015, 7, 14.

33. Tu, R.; Wang, R.; Ge, M.; Walter, T.R.; Ramatschi, M.; Milkereit, C.; Bindi, D.; Dahm, T. Cost-effective monitoring of ground motion related to earthquakes, landslides, or volcanic activity by joint use of a single-frequency GPS and a MEMS accelerometer. Geophys. Res. Lett. 2013, 40, 3825-3829. [CrossRef]

34. de Dios, R.J.C.; Enriquez, J.; Victorino, F.G.; Mendoza, E.A.; Talampas, M.C.; Marciano, J.J. Design, development, and evaluation of a tilt and soil moisture sensor network for slope monitoring applications. In Proceedings of the TENCON 2009-2009 IEEE Region 10 Conference, Singapore, 23-26 January 2009.

35. Marciano, J.S., Jr.; Zarco, M.A.H.; Talampas, M.C.R.; Catane, S.G.; Hilario, C.G.; Zabanal, M.A.B.; Carreon, C.R.C.; Mendoza, E.A.; Kaimo, R.N.; Cordero, C.N. Real-world deployment of a locally-developed tilt and moisture sensor for landslide monitoring in the Philippines. In Proceedings of the 2011 IEEE Global Humanitarian Technology Conference, Seattle, WA, USA, 30 October-1 November 2011.

36. Yang, Z.; Shao, W.; Qiao, J.; Huang, D.; Tian, H.; Lei, X.; Uchimura, T. A Multi-Source Early Warning System of MEMS Based Wireless Monitoring for Rainfall-Induced Landslides. Appl. Sci. 2017, 7, 1234. [CrossRef]

37. Dikshit, A.; Satyam, D.N.; Towhata, I. Early warning system using tilt sensors in Chibo, Kalimpong, Darjeeling Himalayas, India. Nat. Hazards 2018, 94, 727-741. [CrossRef]

38. Towhata, I.; Uchimura, T.; Gallage, C. On early detection and warning against rainfall-induced landslides (m129); Springer: Berlin/Heidelberg, Germany, 2005; pp. 133-139.

39. Uchimura, T.; Towhata, I.; Wang, L.; Seko, I. Development of low-cost early warning system of slope instability for civilian use. In Proceedings of the 17th ISSMGE, Alexandria, Egypt, 5-9 October 2009.

40. Uchimura, T.; Towhata, I.; Anh, T.T.L.; Fukuda, J.; Bautista, C.J.; Wang, L.; Seko, I.; Uchida, T.; Matsuoka, A.; Ito, Y.; et al. Simple monitoring method for precaution of landslides watching tilting and water contents on slopes surface. Landslides 2010, 7, 351-357. [CrossRef]

41. Xie, J.; Uchimura, T.; Chen, P.; Liu, J.; Xie, C.; Shen, Q. A relationship between displacement and tilting angle of the slope surface in shallow landslides. Landslides 2019, 16, 1243-1251. [CrossRef]

42. Xie, J.; Uchimura, T.; Wang, G.; Shen, Q.; Maqsood, Z.; Xie, C.; Liu, J.; Lei, W.; Tao, S.; Chen, P.; et al. A new prediction method for the occurrence of landslides based on the time history of tilting of the slope surface. Landslides 2020, 17, 301-312. [CrossRef]

43. Xie, J.; Uchimura, T.; Wang, G.; Selvarajah, H.; Maqsood, Z.; Shen, Q.; Mei, G.; Qiao, S. Predicting the sliding behavior of rotational landslides based on the tilting measurement of the slope surface. Eng. Geol. 2020, 269, 105554. [CrossRef]

44. Iverson, R.M.; Reid, M.E.; Iverson, N.R.; LaHusen, R.G.; Logan, M.; Mann, J.E.; Brien, D.L. Acute sensitivity of landslide rates to initial soil porosity. Science 2000, 290, 513-516. [CrossRef]

45. Carter, M.; Bentley, S.P. The geometry of slip surfaces beneath landslides: Predictions from surface measurements. Can. Geotech. J. 1985, 22, 234-238. [CrossRef]

46. Carter, M.; Bentley, S.P. A procedure to locate slip surfaces beneath active landslides using surface monitoring data. Comput. Geotech. 1985, 1, 139-153. [CrossRef]

47. Ulusay, R.; Aksoy, H. Assessment of the failure mechanism of a highwall slope under spoil pile loadings at a coal mine. Eng. Geol. 1994, 38, 117-134. [CrossRef]

48. Baum, R.L.; Messerich, J.; Fleming, R.W. Surface deformation as a guide to kinematics and three-dimensional shape of slow-moving, clay-rich landslides, Honolulu, Hawaii. Environ. Eng. Geosci. 1998, 4, $283-306$. [CrossRef]

49. Michel, J.; Dario, C.; Marc-Henri, D.; Thierry, O.; Marina, P.I.; Bejamin, R. A review of methods used to estimate initial landslide failure surface depths and volumes. Eng. Geol. 2020, 105478. [CrossRef]

(C) 2020 by the authors. Licensee MDPI, Basel, Switzerland. This article is an open access article distributed under the terms and conditions of the Creative Commons Attribution (CC BY) license (http://creativecommons.org/licenses/by/4.0/). 